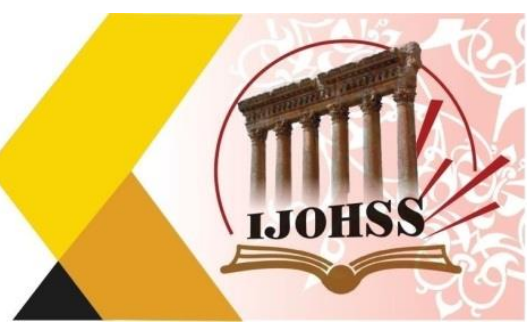

\title{
الانحياز اللغوي بين الذات والآخر
}

$$
\begin{aligned}
& \text { م. م. حلا حليبد شرشاب الحسيناوي } \\
& \text { أ.د. ناجي عباس مطر الركابي } \\
& \text { قسم اللغة العربية ـ كلية الآداب } \\
& \text { جامعة ذي قار - العراق الآداب }
\end{aligned}
$$

تقوم العلاقة بين الرجل و المر أة على أساس الهيمنة والتراتبية في توزيع الأدوار و الصفات، والهيمنة الذكارة الفورية

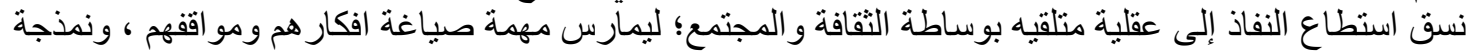
شخصياتهم بالثكل الذي يخدم هذه التراتبية ويؤبدها، وقد مارست اللغة مهمة تمريره وشر عنته وتأبيده، فهي

متحيزة بكل صيغها وابنيتها.

الكلمات المفتاحية: الهيمنة، الذكورة، الأنوثة، تمايز واختلاف.

\section{Linguistic Bias between the Self and the Other}

\author{
Hala Halibd Sharshab Al-Husseinawi \\ Prof. Dr. Naji Abbas Matar Al-Rikabi \\ Department of Arabic Language - Faculty of Arts \\ Dhi Qar University - Iraq
}

\begin{abstract}
The relationship between man and women based on domination and hierarchy in the distribution of roles and characteristics, and the male dominanted pattern was able to access into the minds of recipients through culture and society to practice the task of formulating their mindsets and attitudes, and modeling their personalities in a way that serves and supports this hierarchy, and the language exercised the task of passing it on and legitimizing because it's biased in all its formulations and structures.
\end{abstract}

Keywords: Dominance, masculinity, femininity, differentiation and difference. 


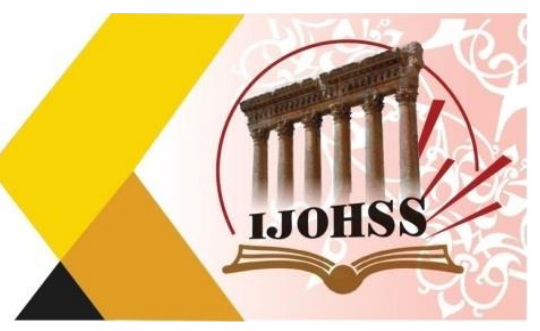

هيمن التباين في قيم الذكورة والأنوثة على كل شيء أحاط بعالمي المرأة والرجل، فهو متجلِّ في الأدوار

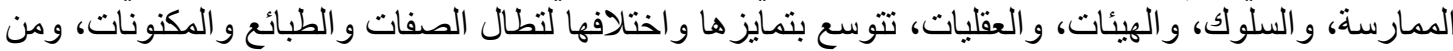

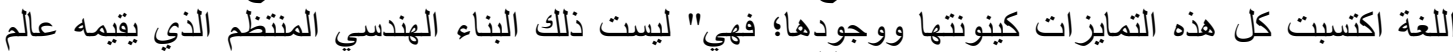

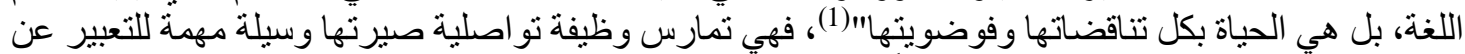

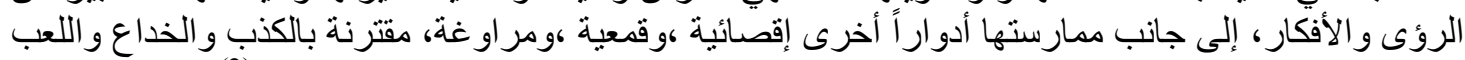

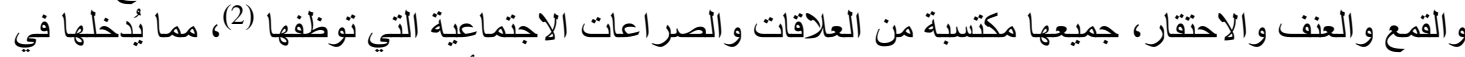

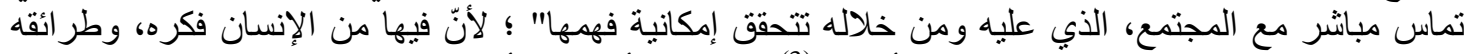

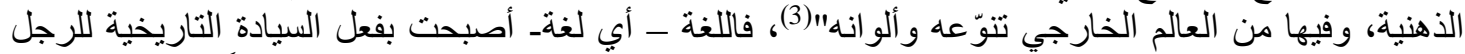

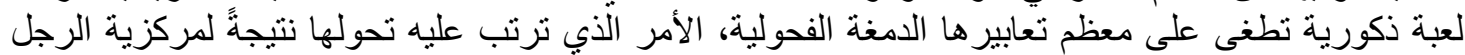

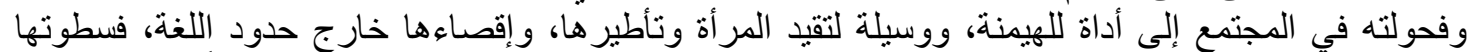

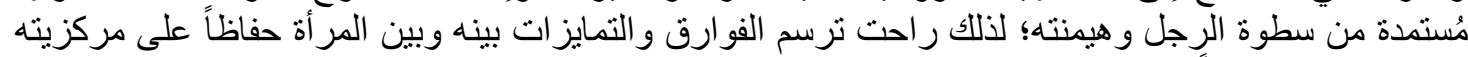

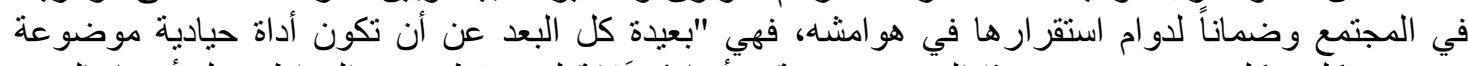

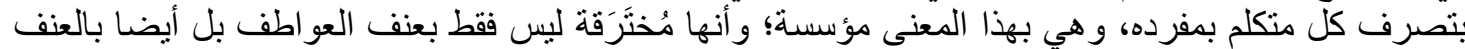

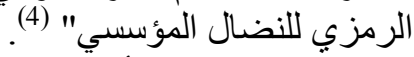

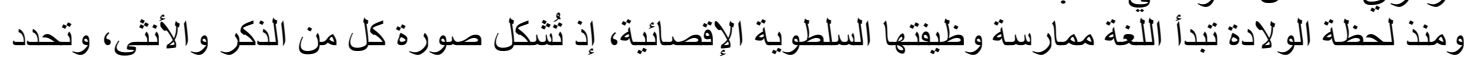

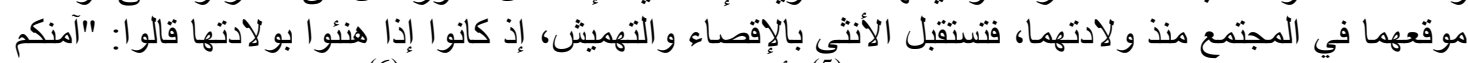

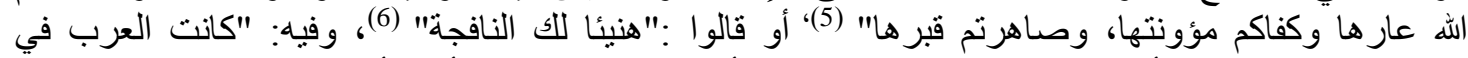

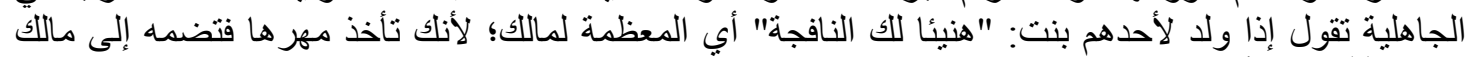

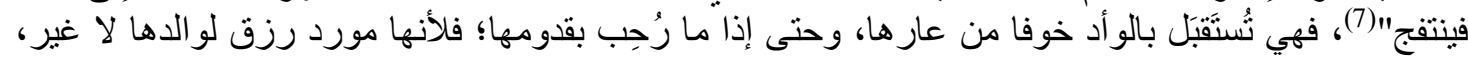

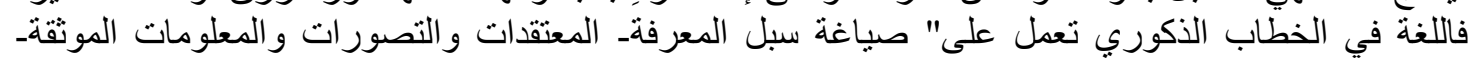

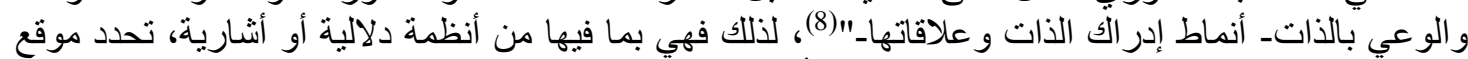

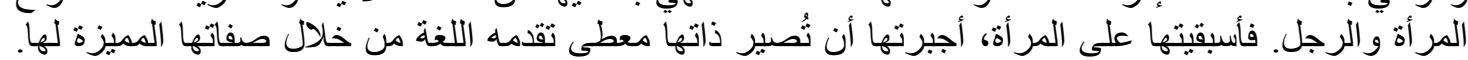

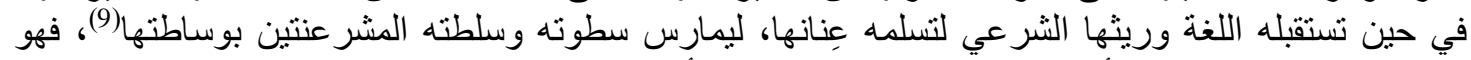

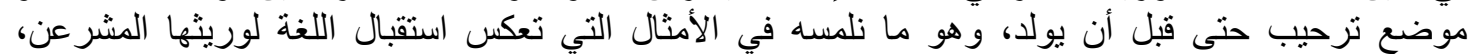

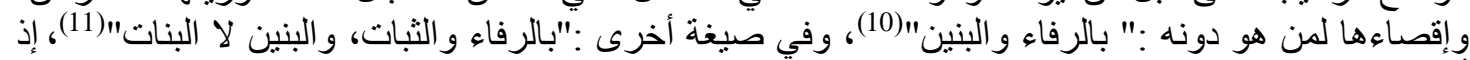

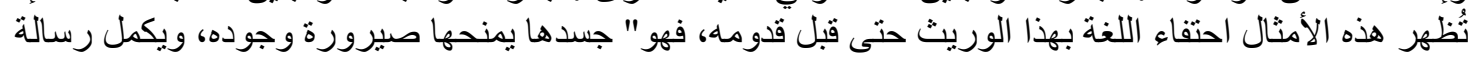

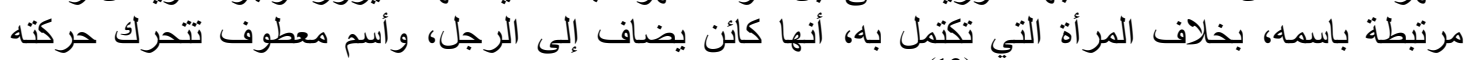

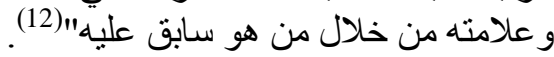

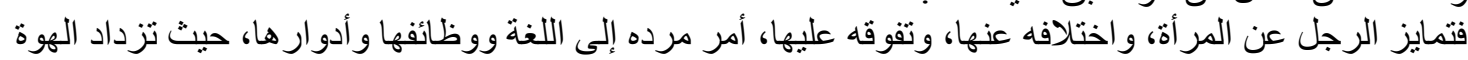

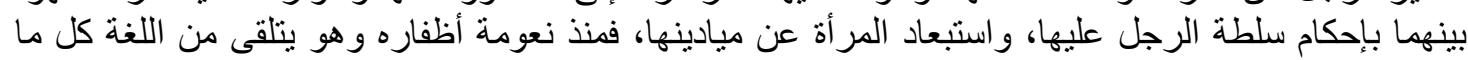

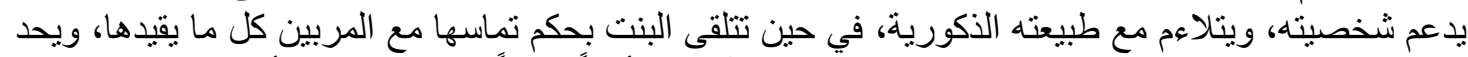

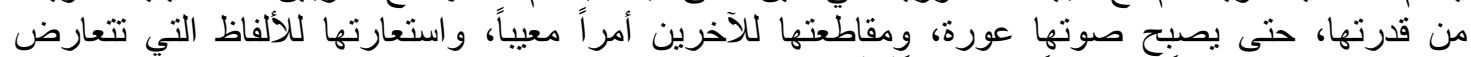

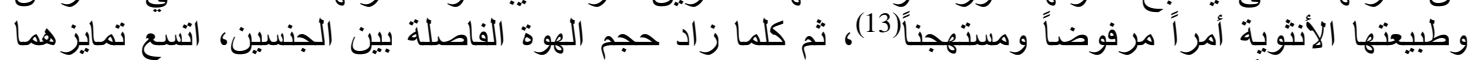

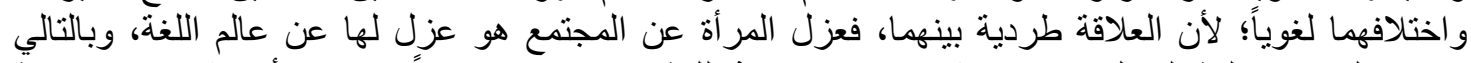

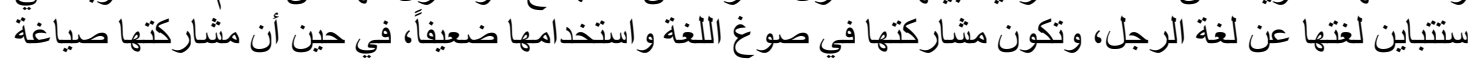

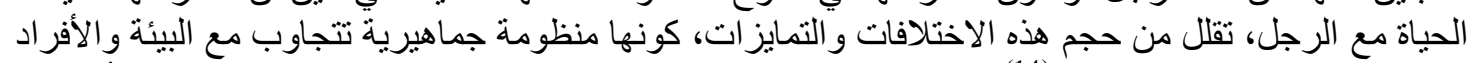

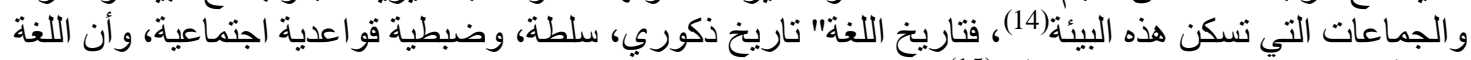

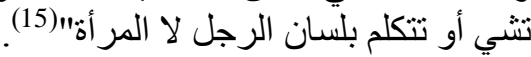

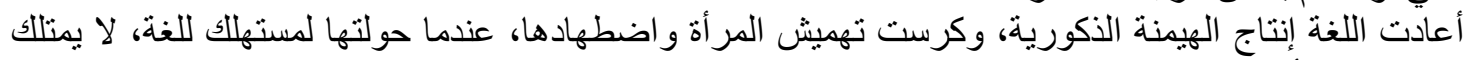

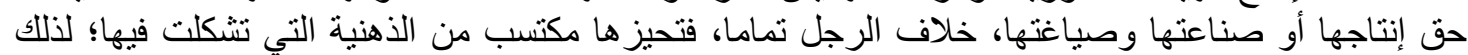

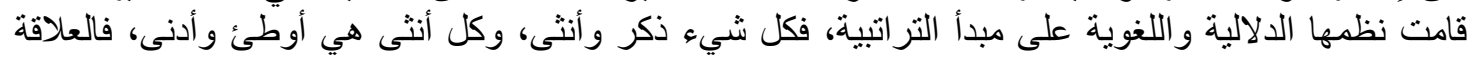
بينهما كما يرسمها اللسان اللغوي قائمة على الإختلاف فقد جاء في اللساء فلان: 


\section{المبلة اللحولية اللملوم الآنسانية والإمتماعية}

International Journal on Humanities and Social Sciences website:www.ijohss.com Email:editor@ijohss.com ISSN: 2415 - 4822

\section{العدد (20) Volume (20) April 2021}

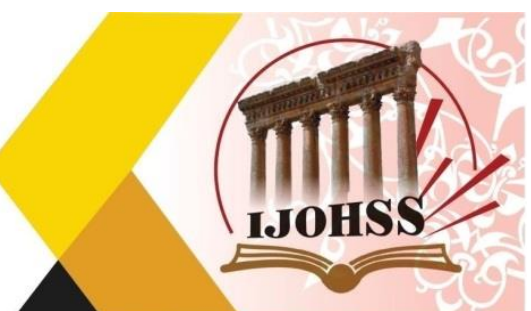

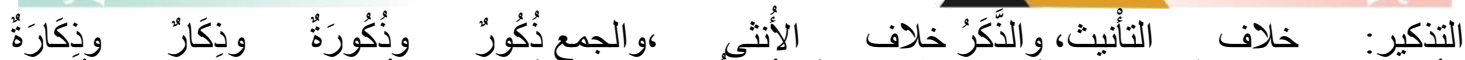

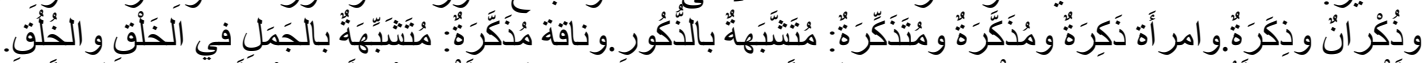

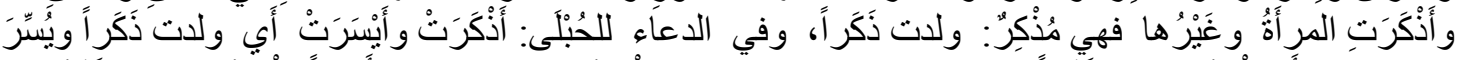

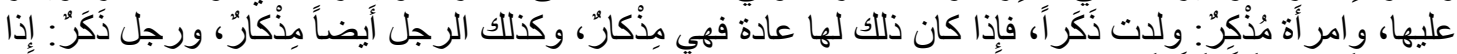

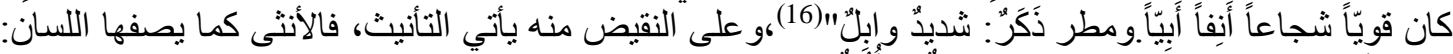

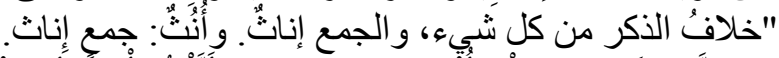

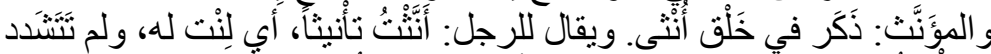

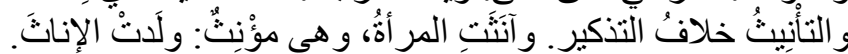

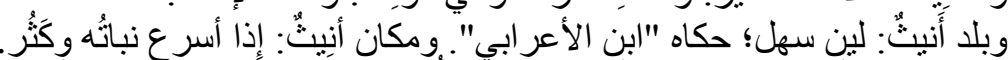

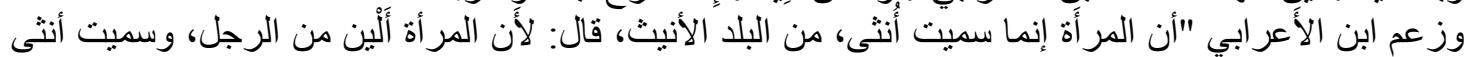
للينها" (17).

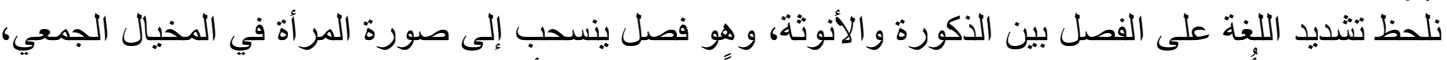

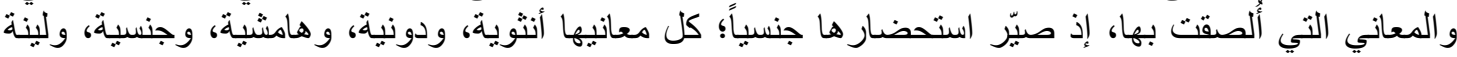

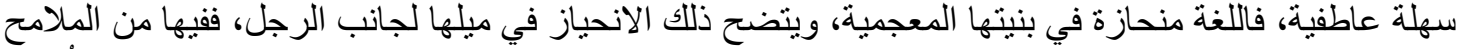

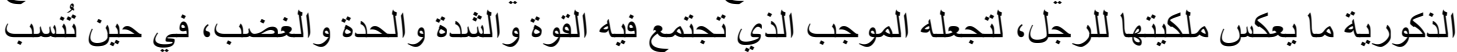

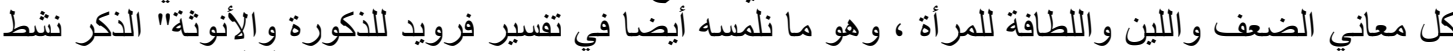

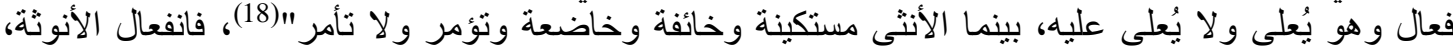

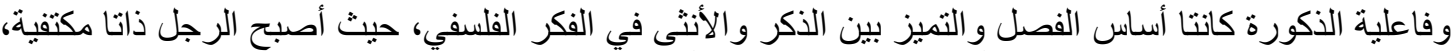

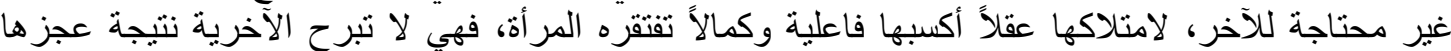
و وانفعالها (19).

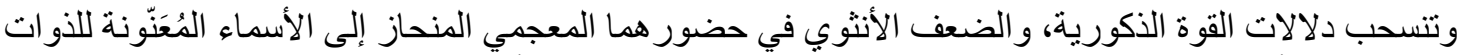

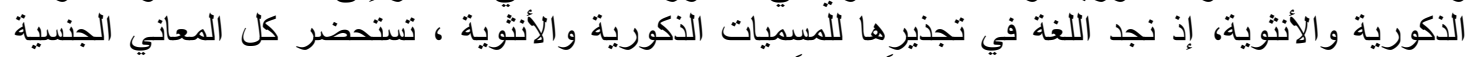

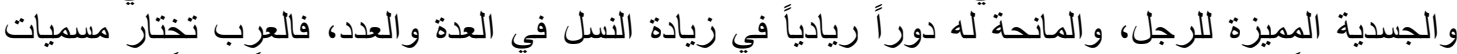

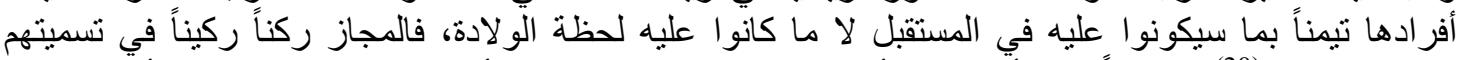

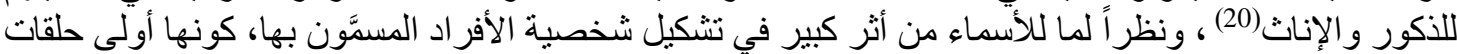

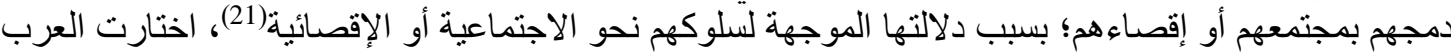

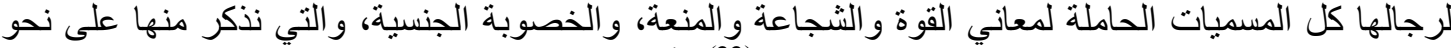

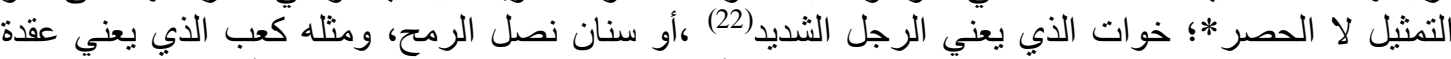

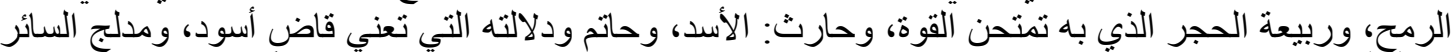

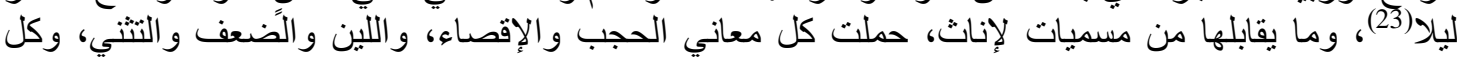

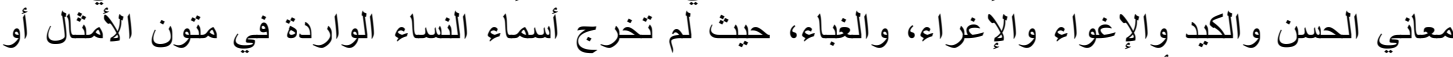

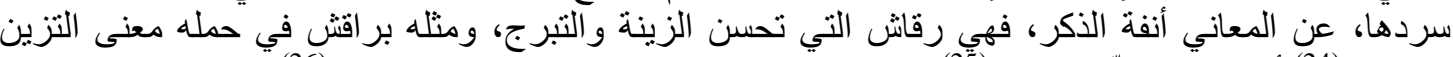

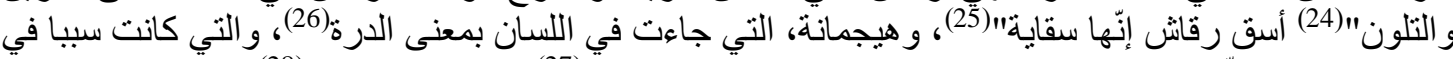

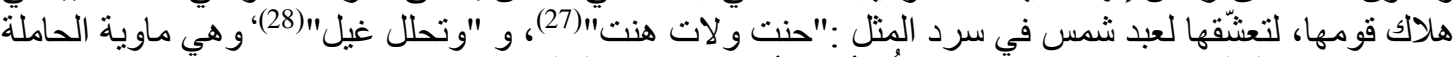

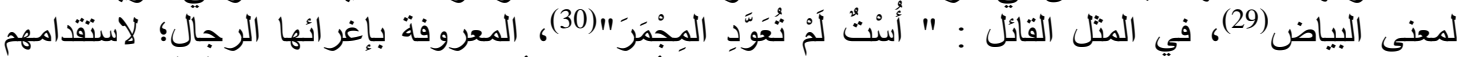

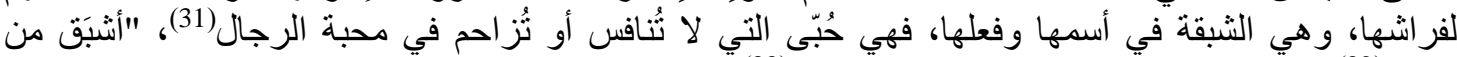

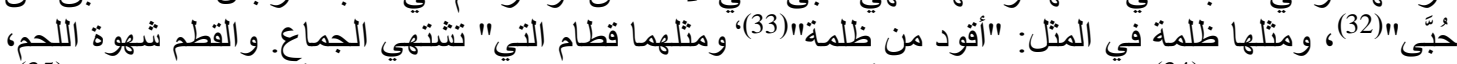

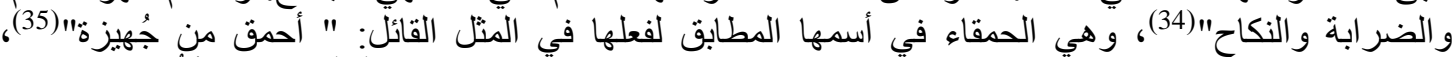

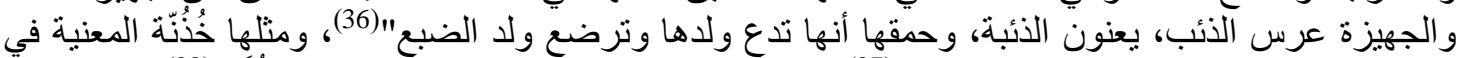

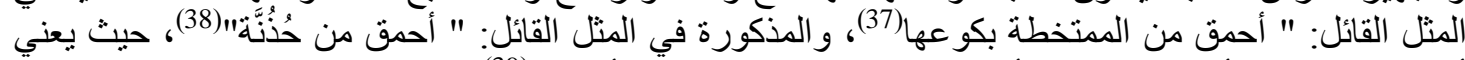

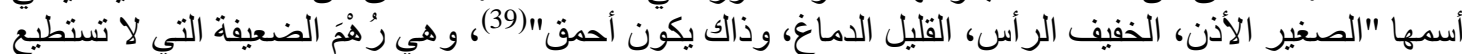

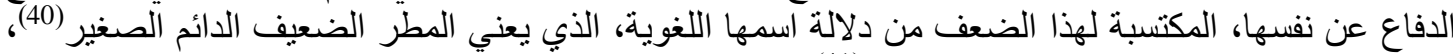

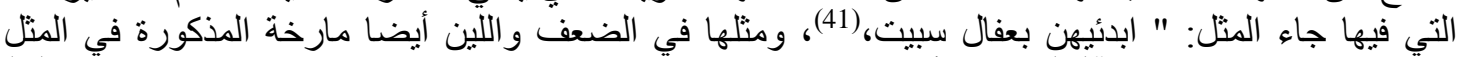

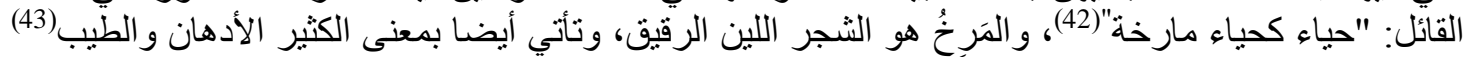




\section{العدد (20) Volume (20) April 2021}

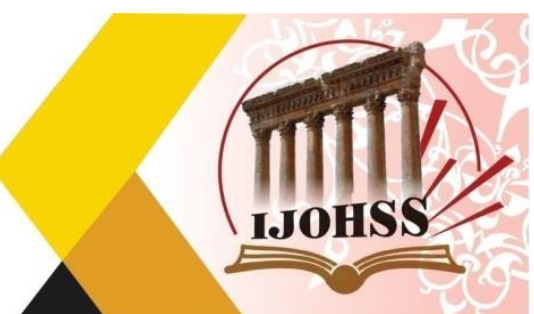

جاء فيه: " أن امر أة يقال لها مارخة نزلت بقوم، فقدمو الها قرى، فقالت: أستحي أن أصيب منه وخرجت ألهاء عنهم،

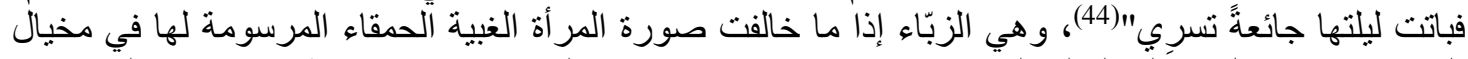

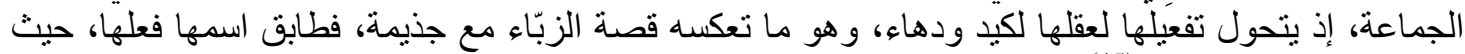

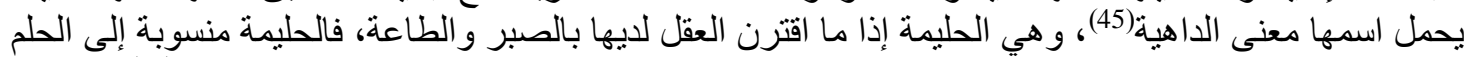

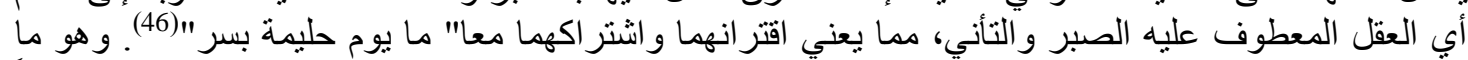

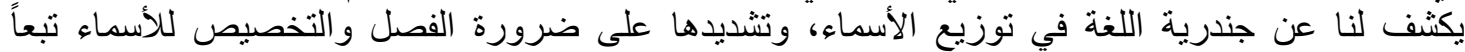

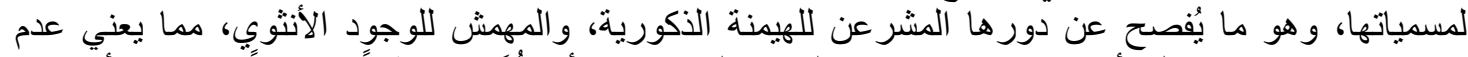

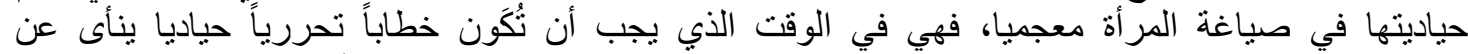

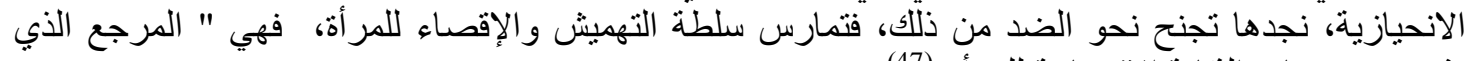

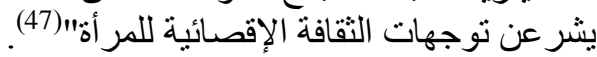

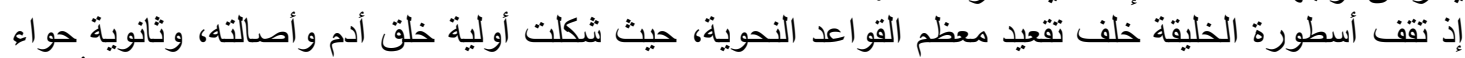

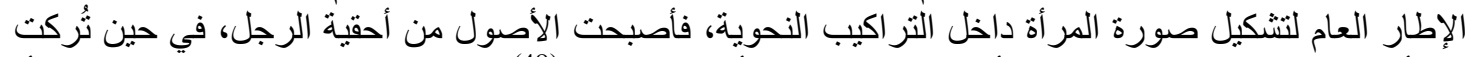

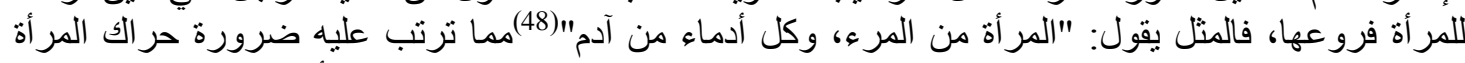

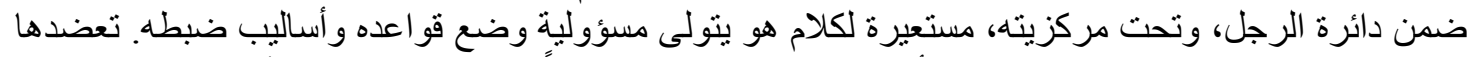

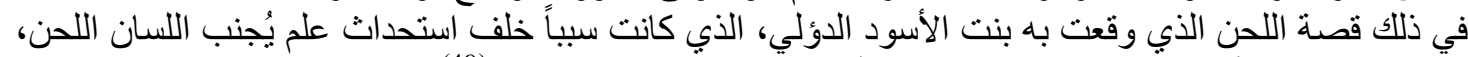

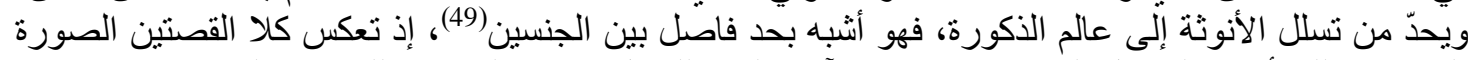

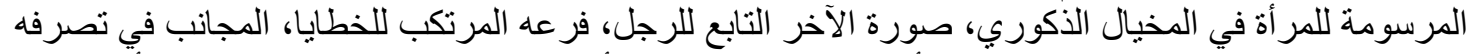

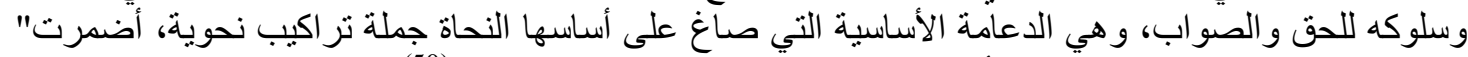

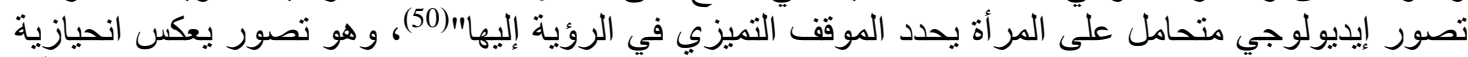

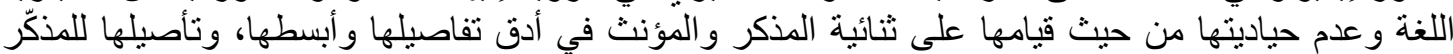

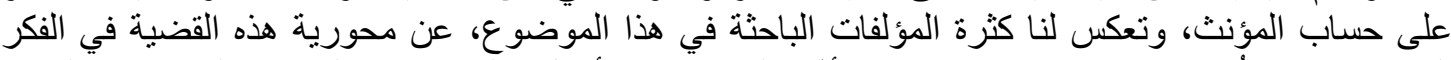

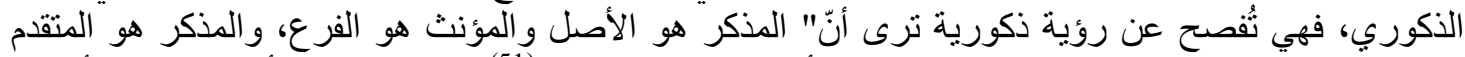

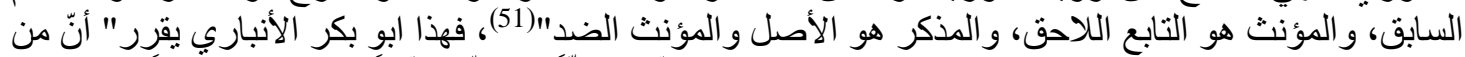

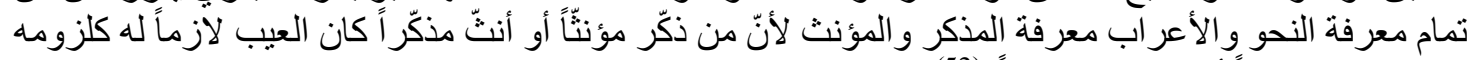

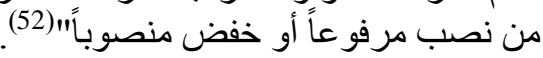

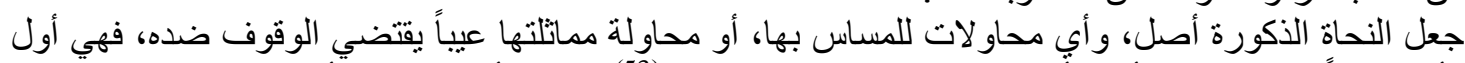

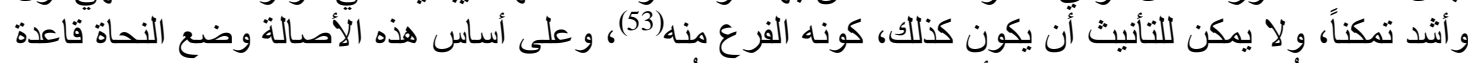

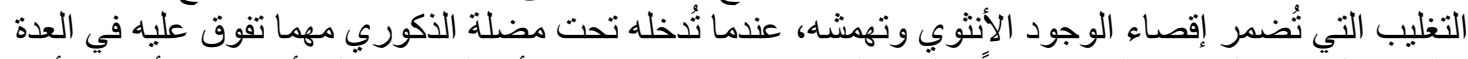

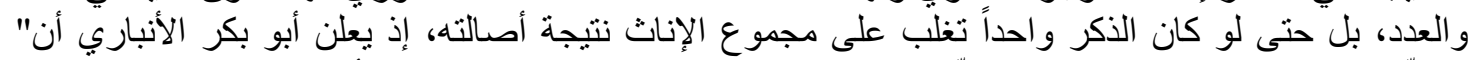

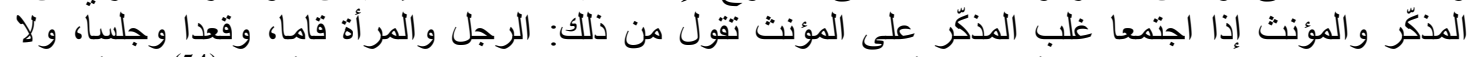

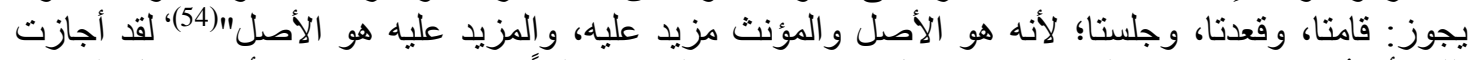

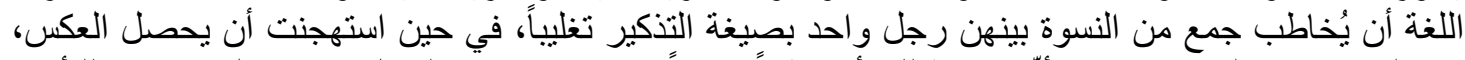

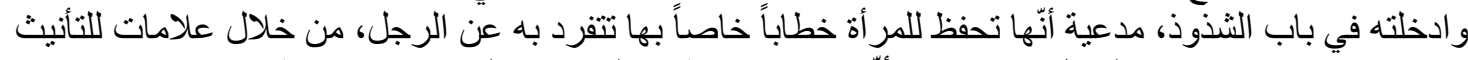

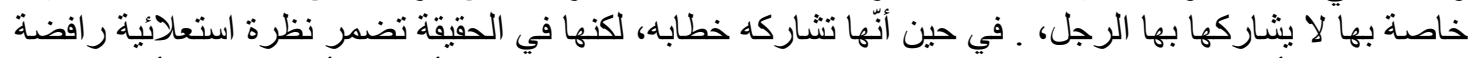

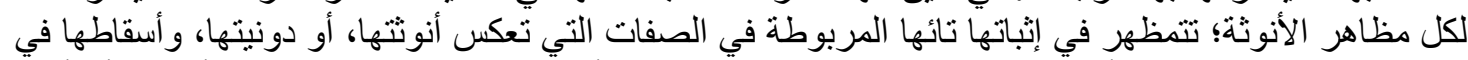

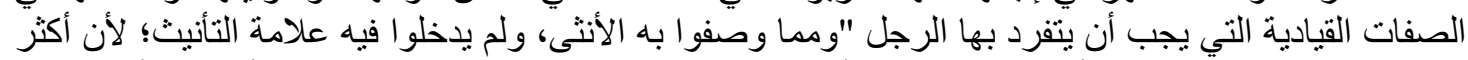

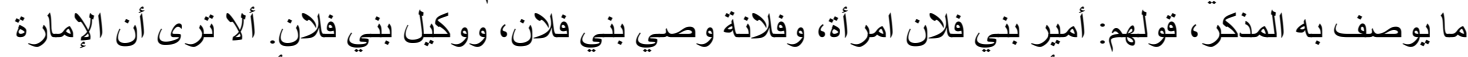

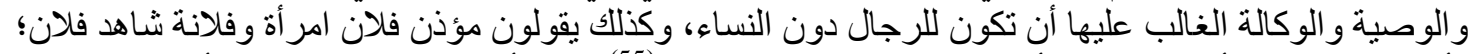

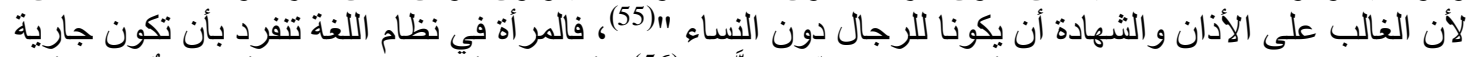

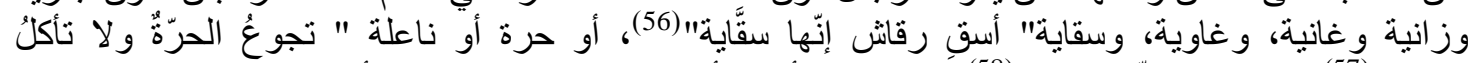

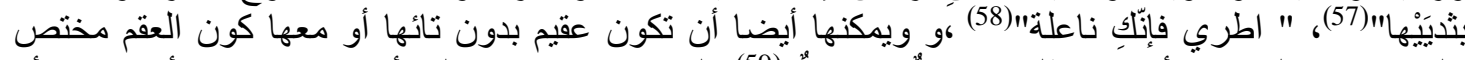

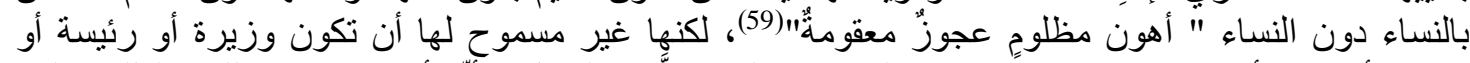

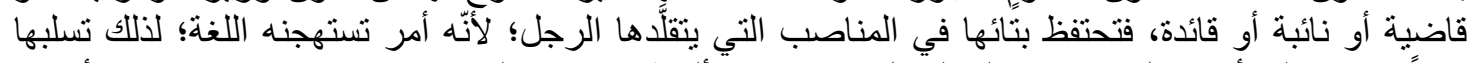

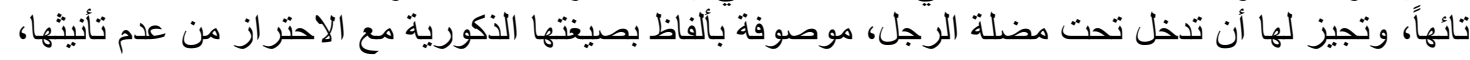




\section{العدد (20) \\ Volume (20) April 2021}

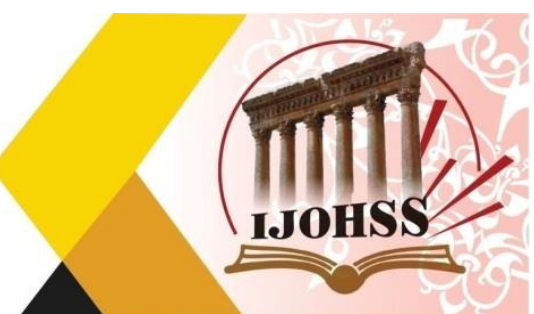

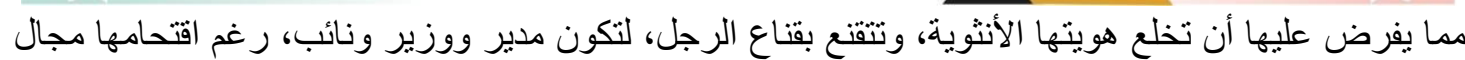

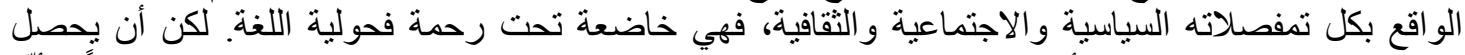

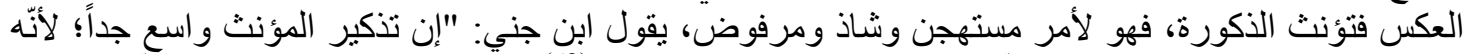

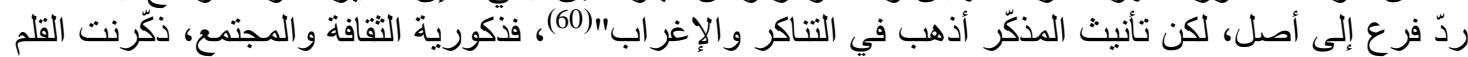

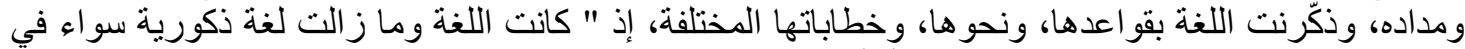

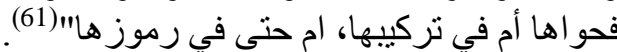

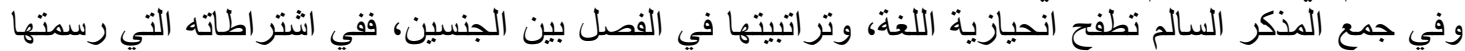

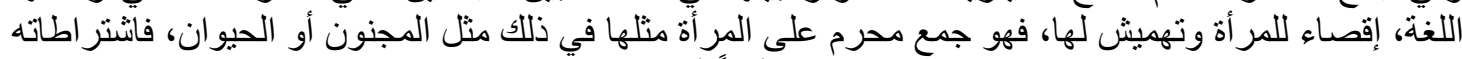

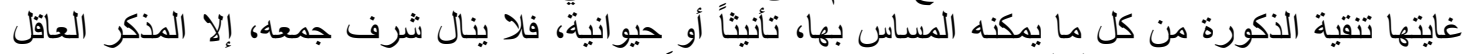

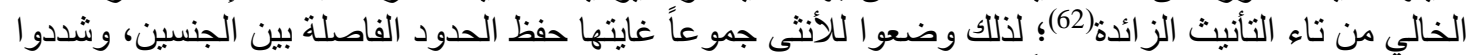

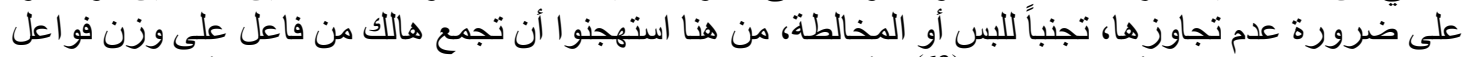

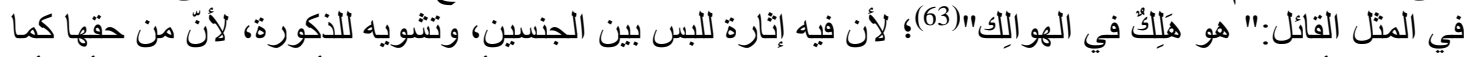

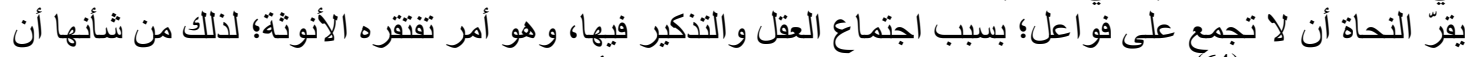

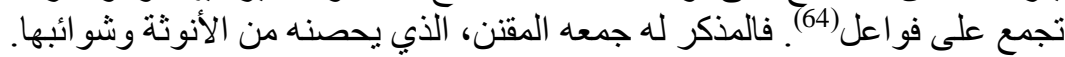

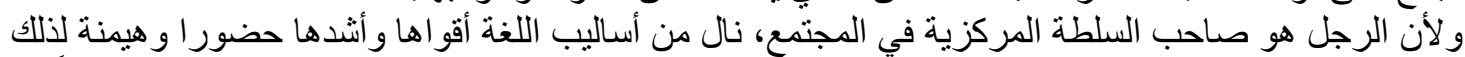

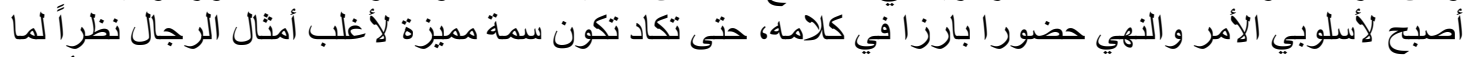

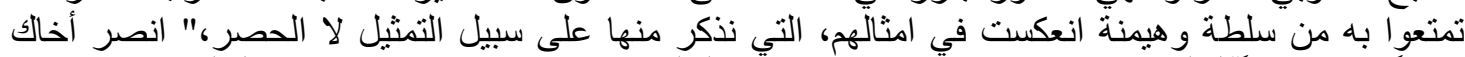

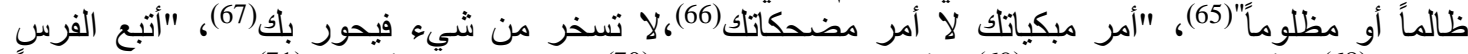

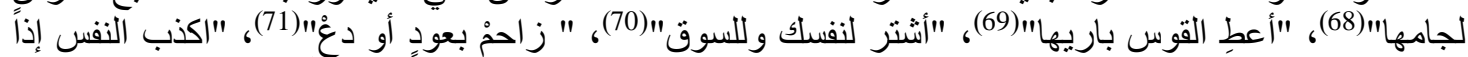

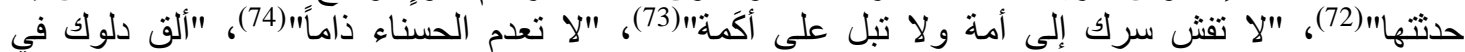

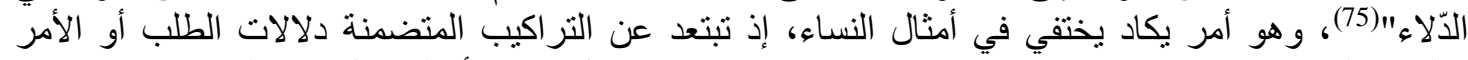

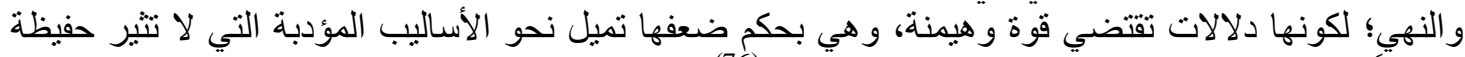

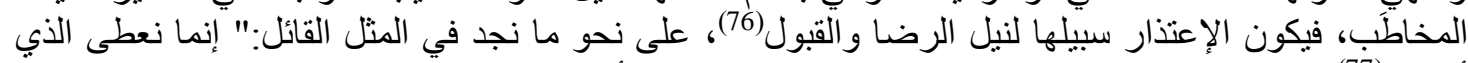

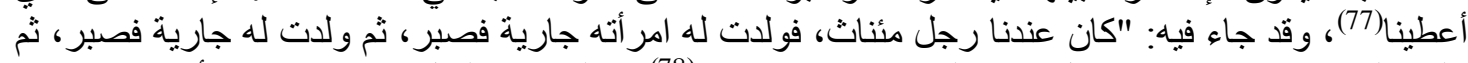

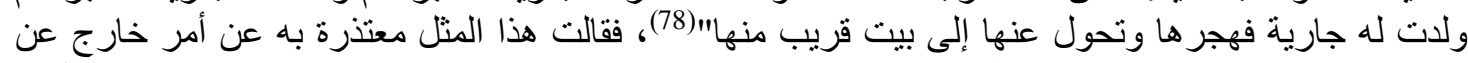

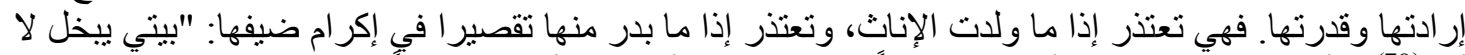

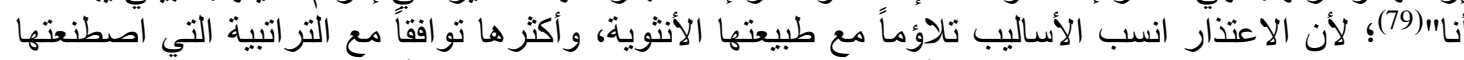

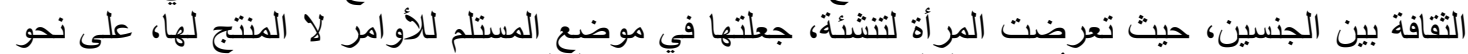

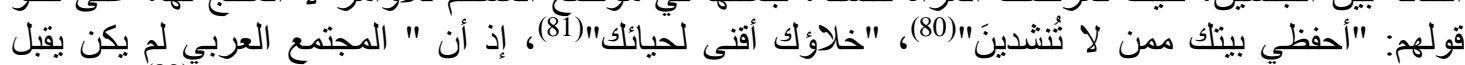

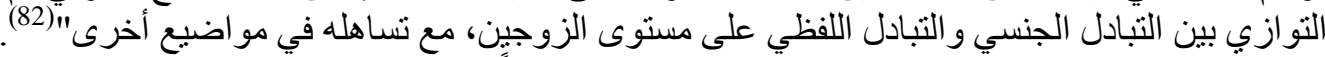

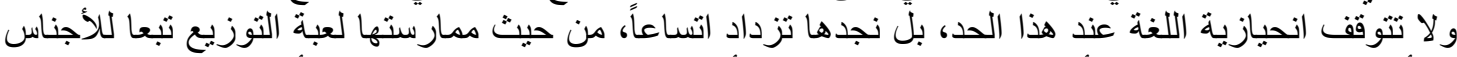

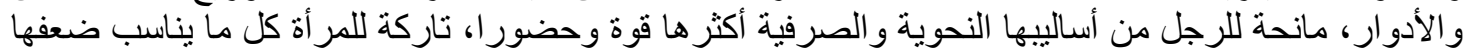

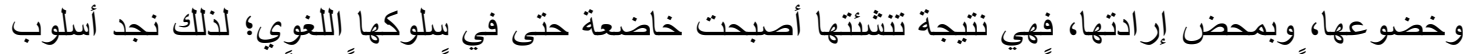

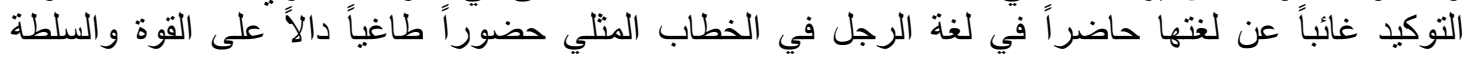

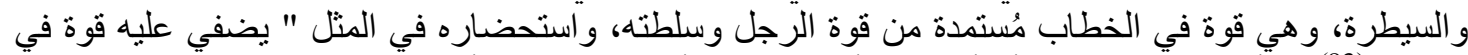

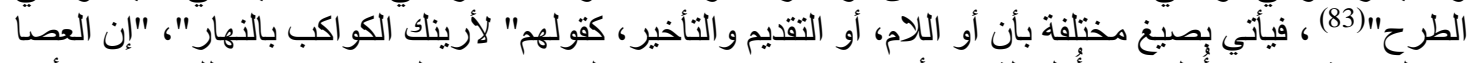

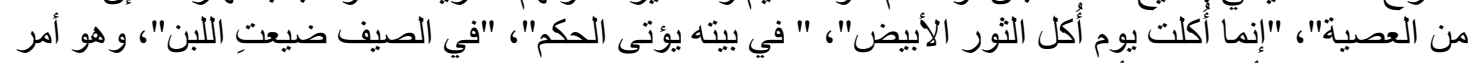

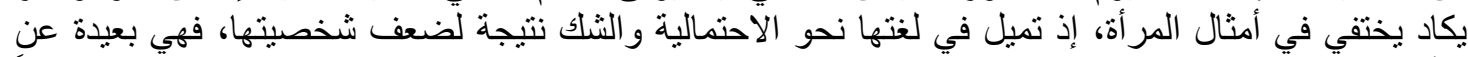

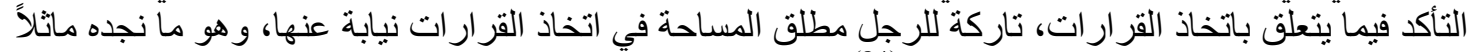

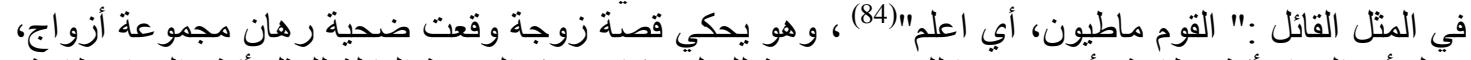
حول أي النساء أكثر طاعة لأمر زوجها للسير في قرية للنمل، فكانت هذه الزوجة التهائلة التهائة للمثل أكثر النساء طاعة؛

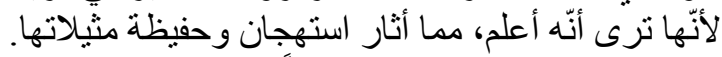

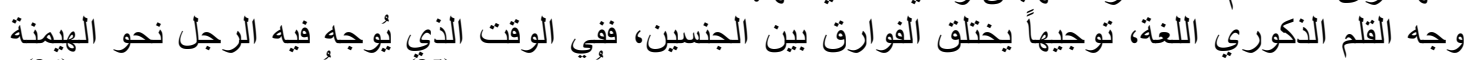

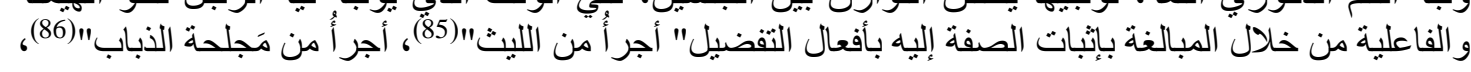


International Journal on Humanities and Social Sciences

website:www.ijohss.com

Email:editor@ijohss.com

ISSN: 2415 - 4822

$\begin{array}{ccc}2021 & \text { أبريل } 2021 \\ \text { Volume (20) April } 2021\end{array}$

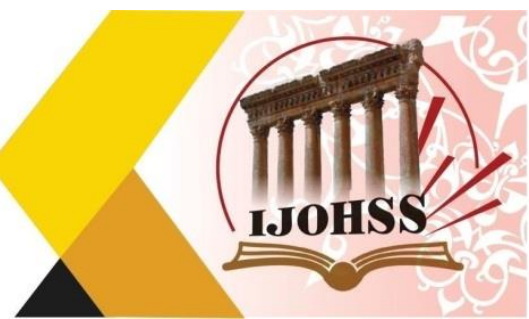

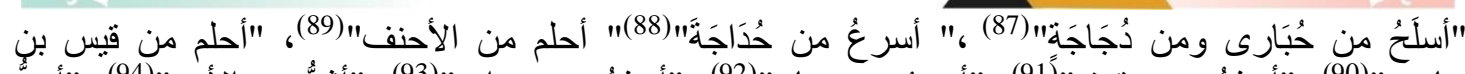

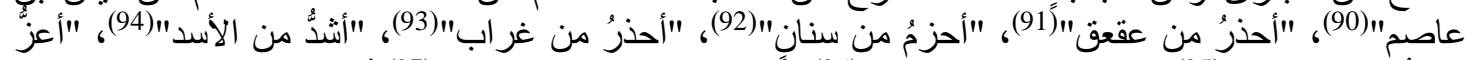

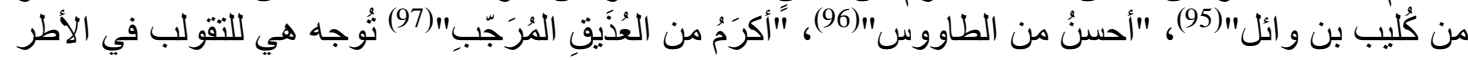

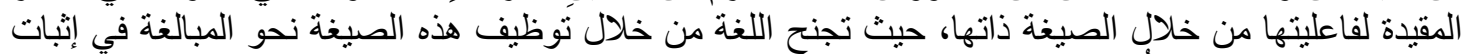

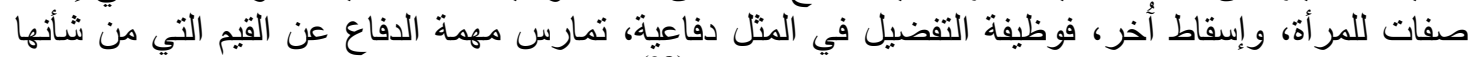

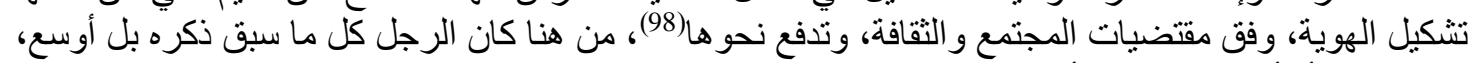

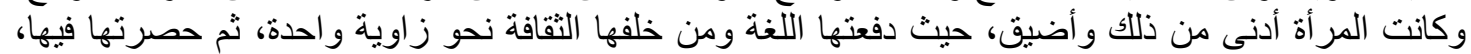

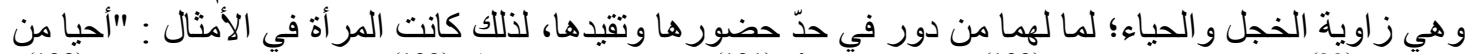

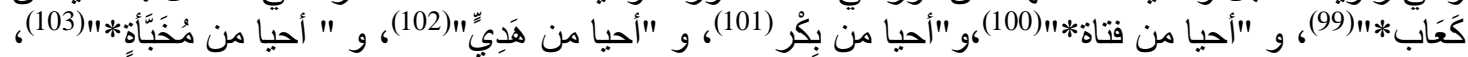

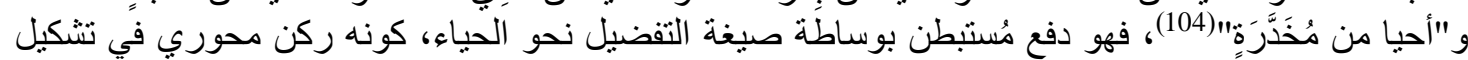

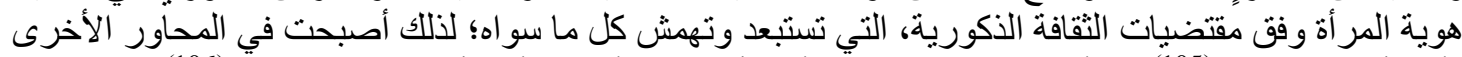

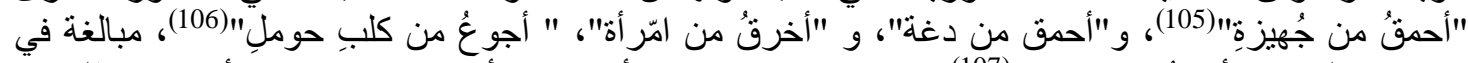

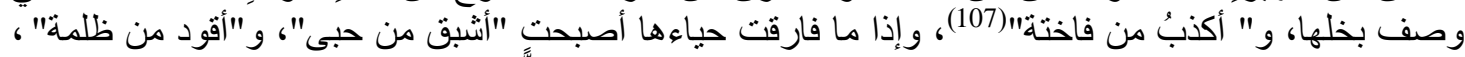

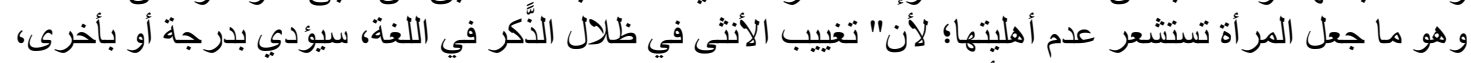

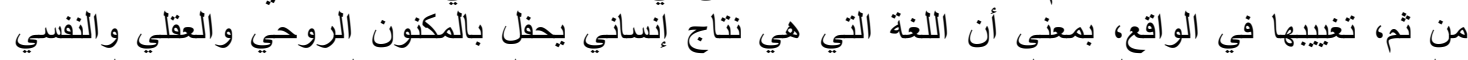

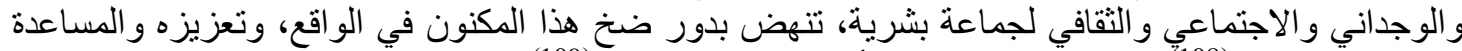

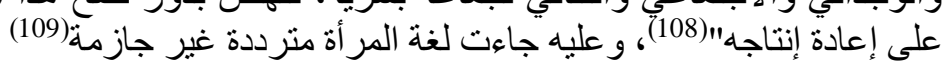

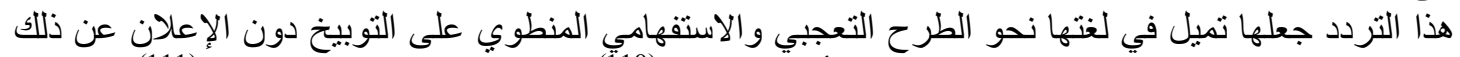

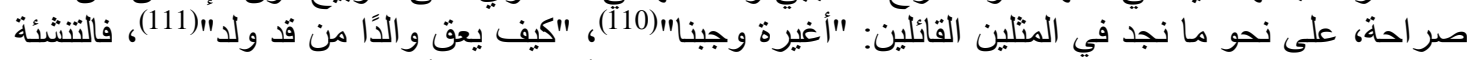

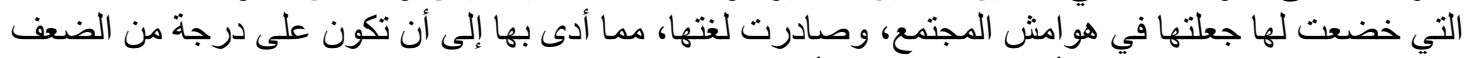

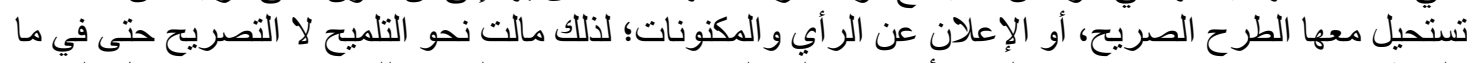

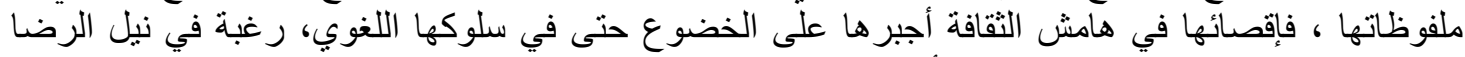

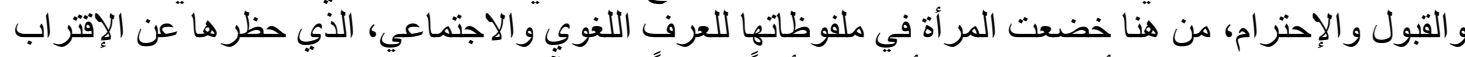

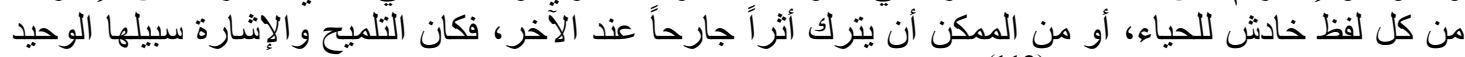

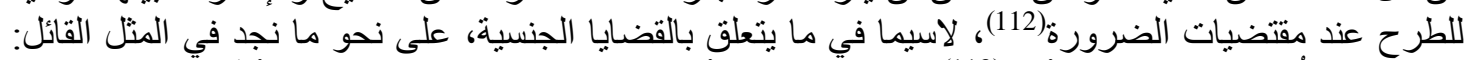

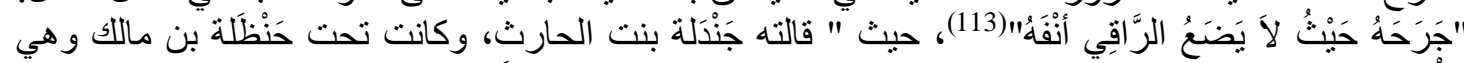

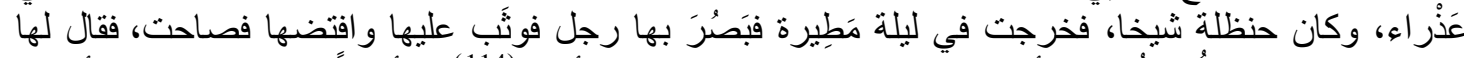

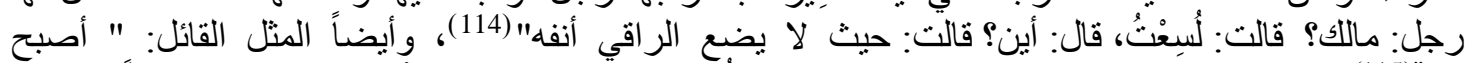

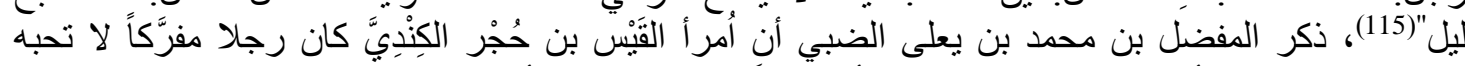

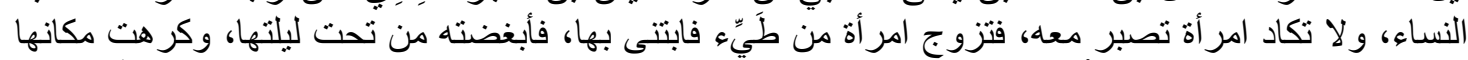

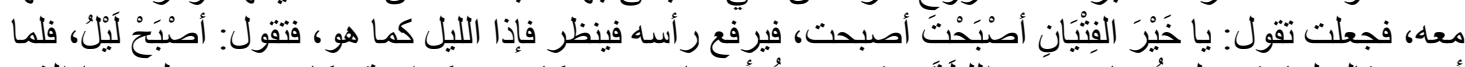

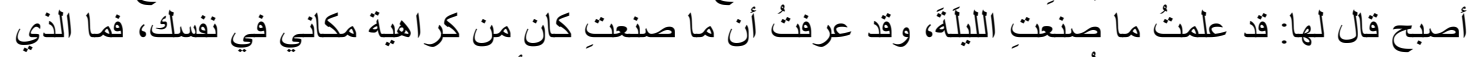

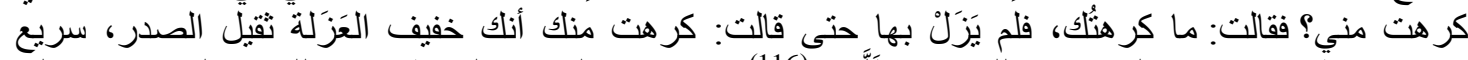

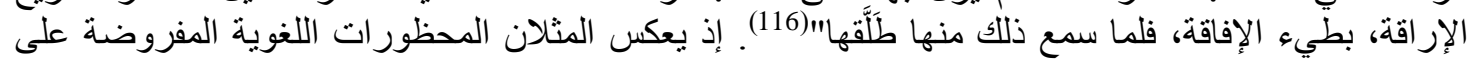

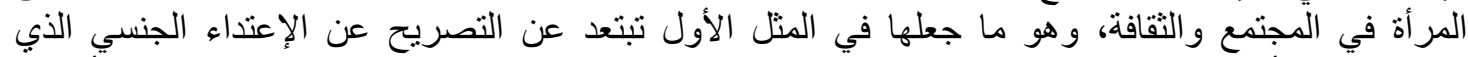

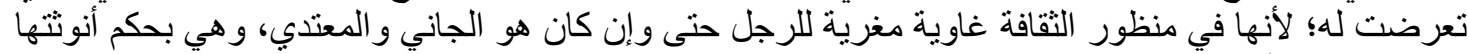

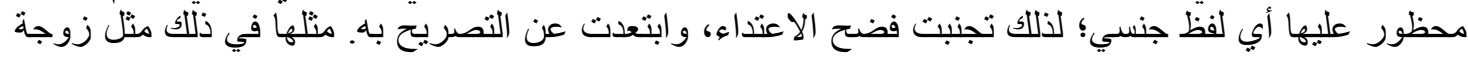

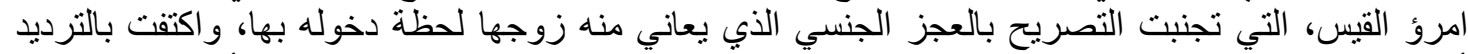

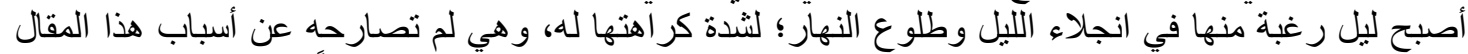

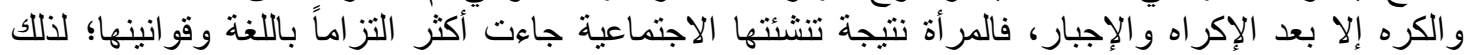

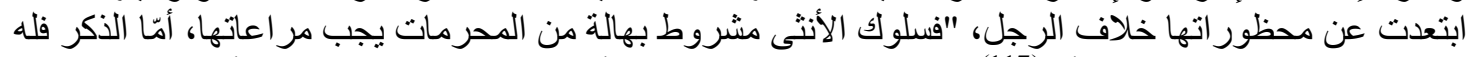

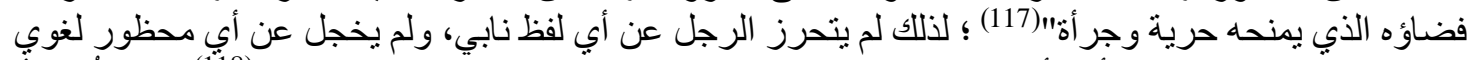

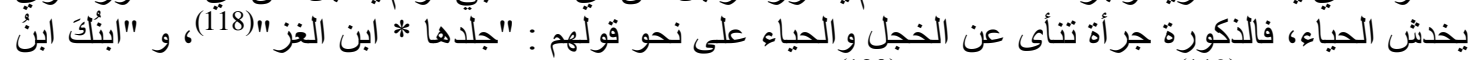

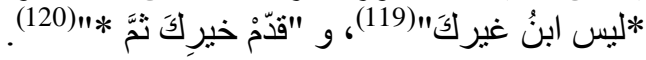




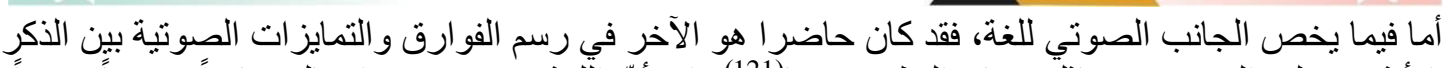

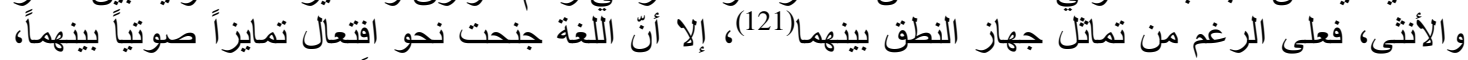

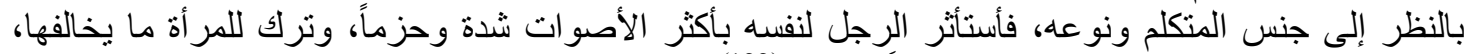

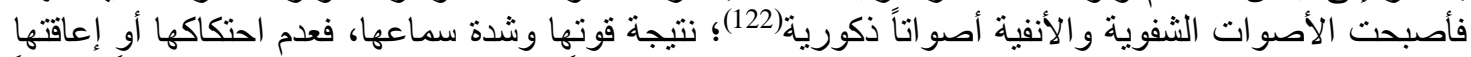

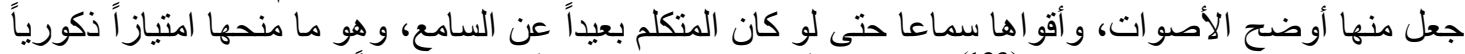

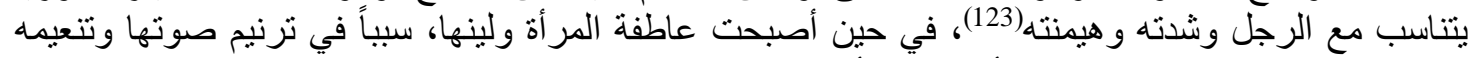

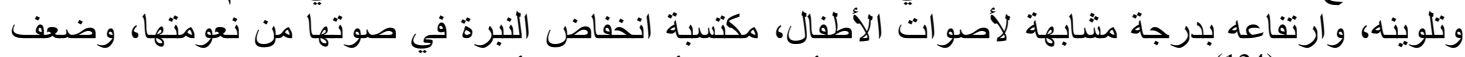

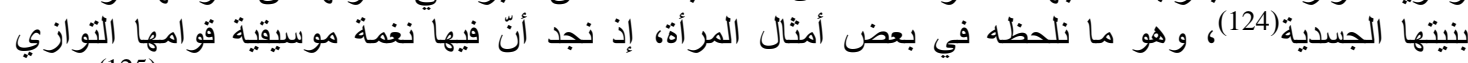

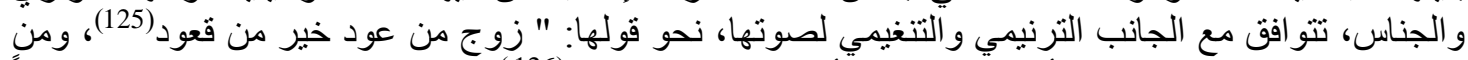

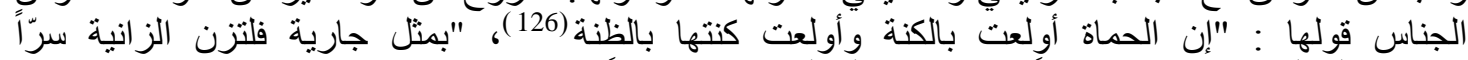

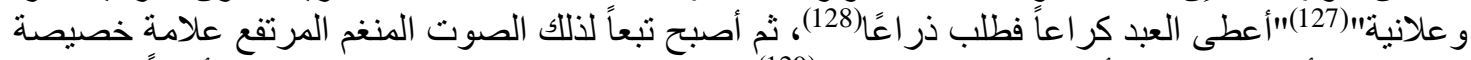

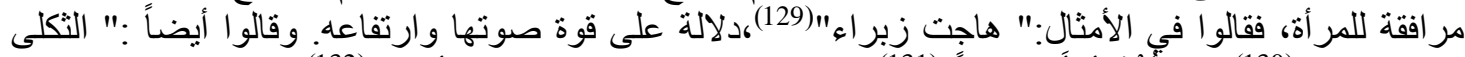

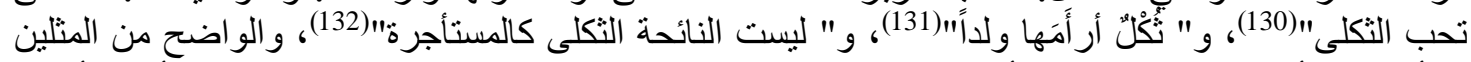

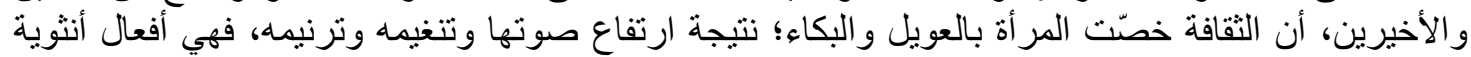

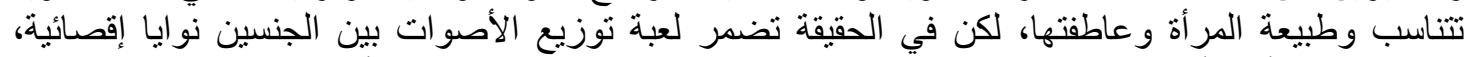

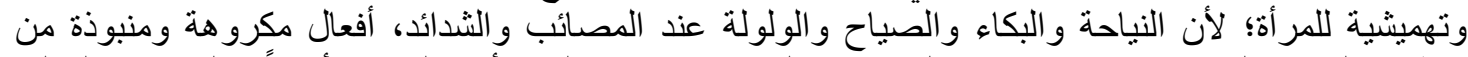
منظور الدين والثريعة، فقد جاء في الحديث " ليس منا من صلق * أو أو حلق"، و أيضاً:" لعن الله السّالقة و والحالقة" (133).

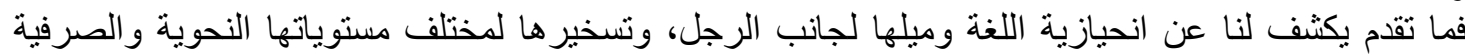

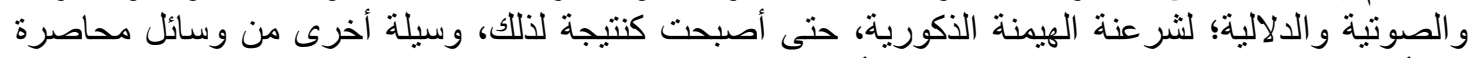

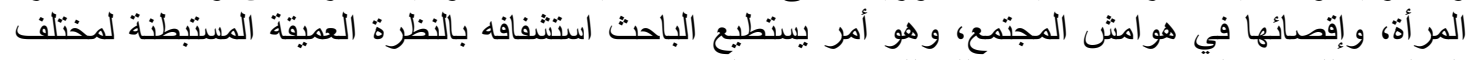

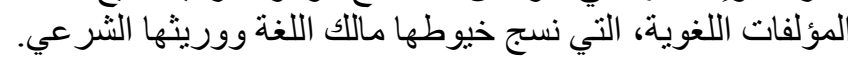

اللهوامش

(1) عنف اللغة، جان جاك لوسركل، ترجمة محمد بدوي، مراجعة سعد مصلوح، الدار العربية للعلوم، المركز الثقافي

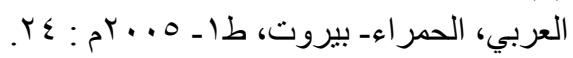

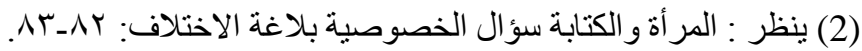

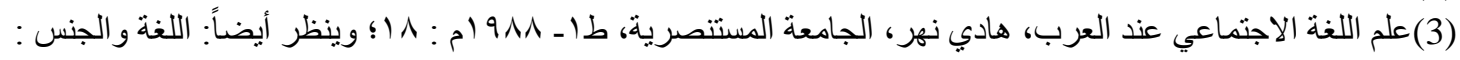

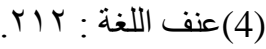

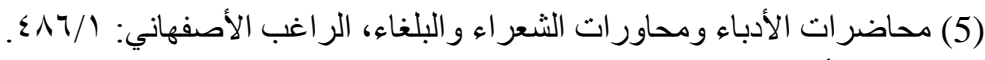

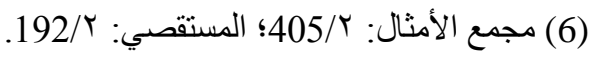

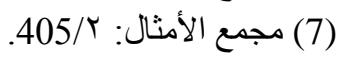

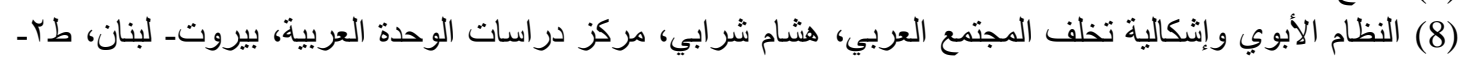

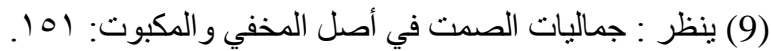

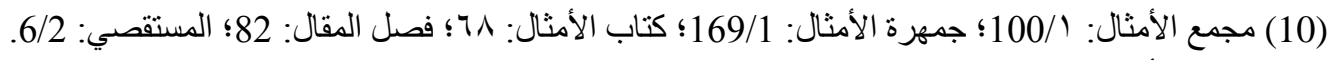

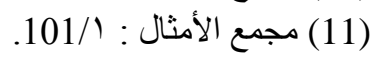

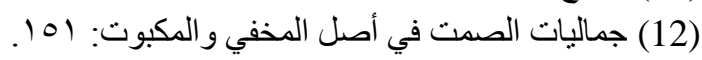

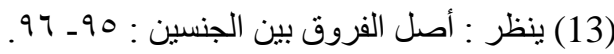

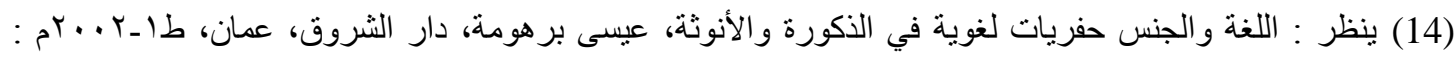




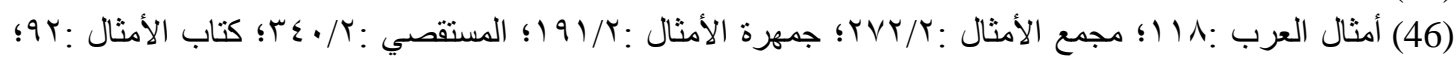

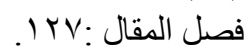
(47) قيمة الأنوثة المتدنية رؤية في التراث النقاثي عند العرب، جابر خضير جبر، مجلة القادسية في الأداب والعلوم

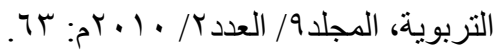

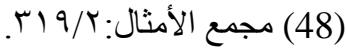

(49) ينظر: جماليات الصمت في أصل الحخفي و المكبوت: 101 10؛ وينظر ايضا : المرأة والكتابة سؤال الخصوصية بلاغة 


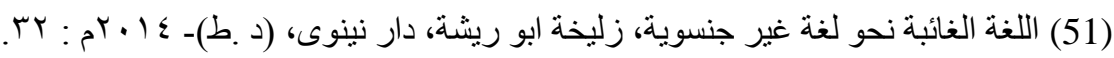

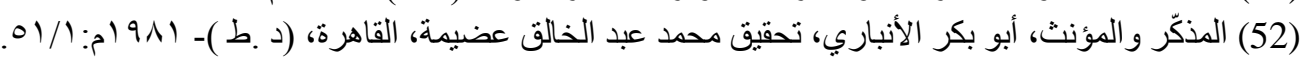

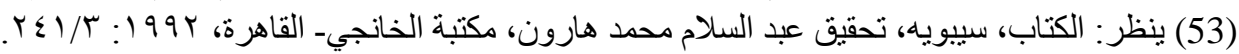

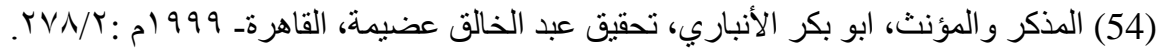

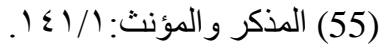

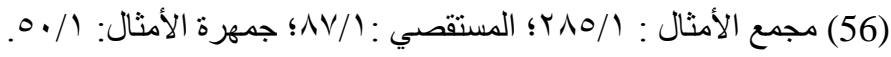

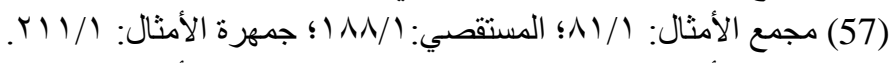

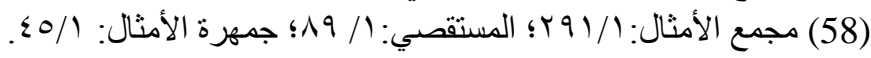

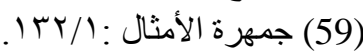

(60) الخصائص، ابو الفتح عثمان ابن جني، تحقيق محمد علي النجار، تقديم عبد الحكيم الراضي، الهيئة العامة لقصور

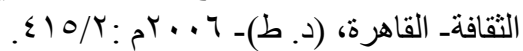

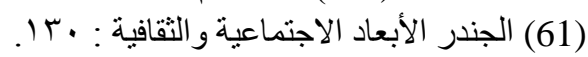

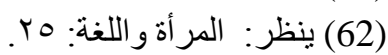

(63) الموشح في مآخذ العلماء على الثعراء، للمرزباني، تحقيق محمد حسين شمس الدين، دار الكتب العلمية، بيروتـ

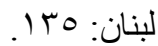

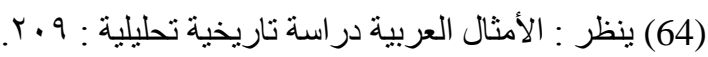

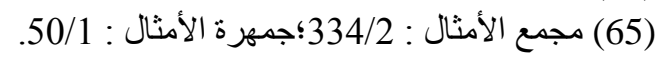

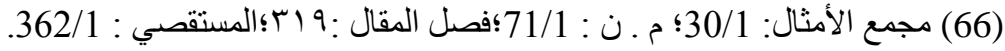

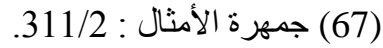

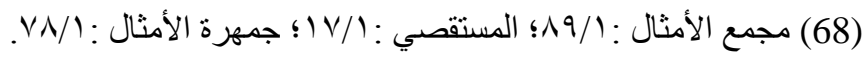

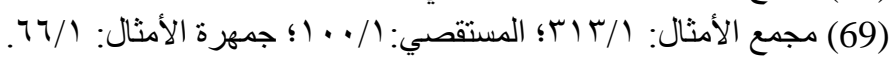

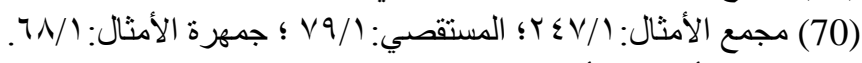

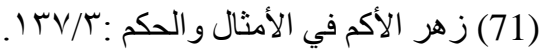

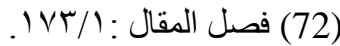

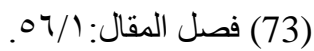

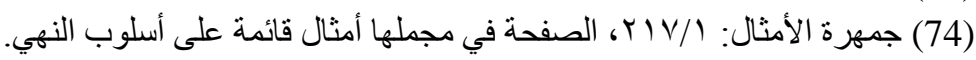

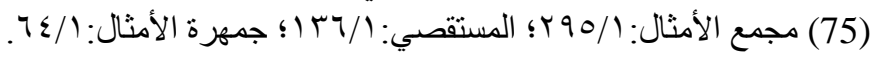

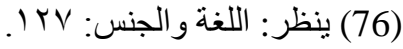

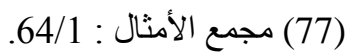

(78)

(9Y/1:

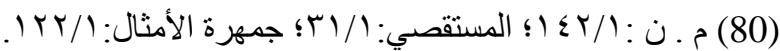

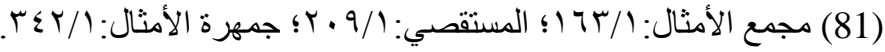

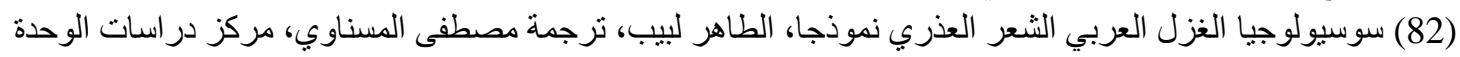

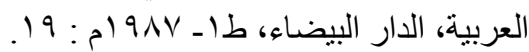

(83) لغة المثل العربي دراسة وصفية تحليلية، حنان إسماعيل عمايرة، فوز سهيل نز الإل، مجلة الجامعة الإسلامية للبحوث

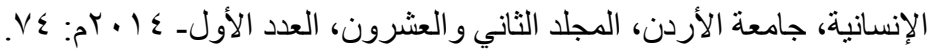

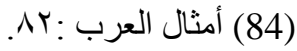

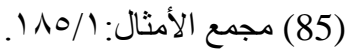

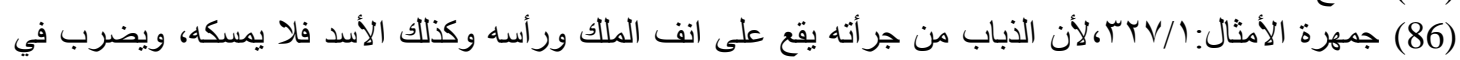

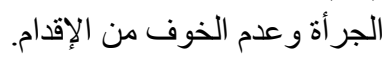




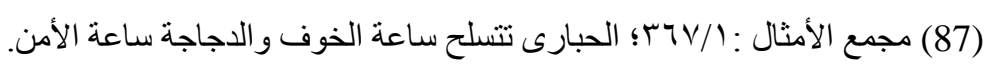

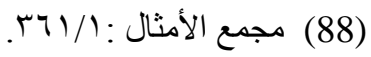

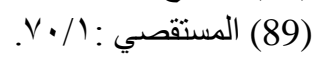

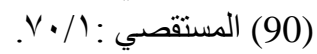

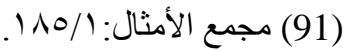

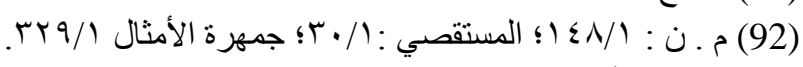

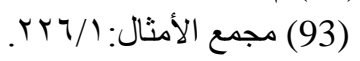

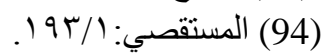

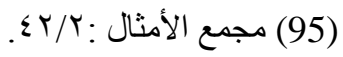

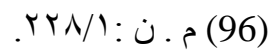

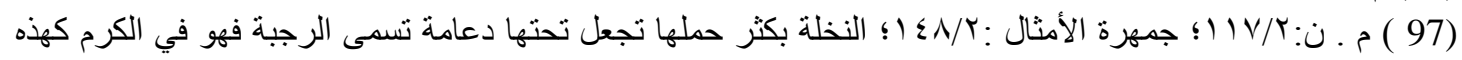

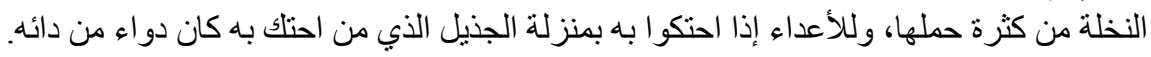

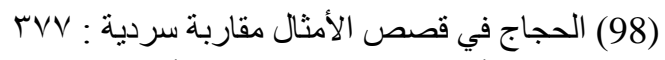

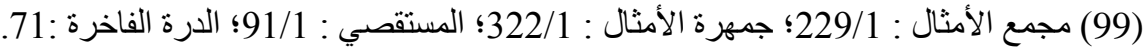

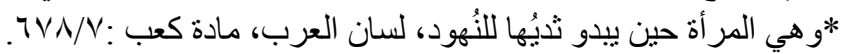

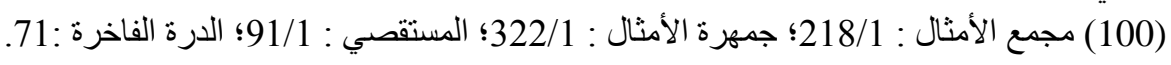

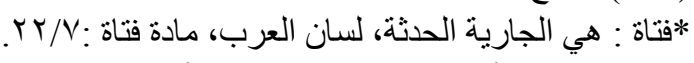

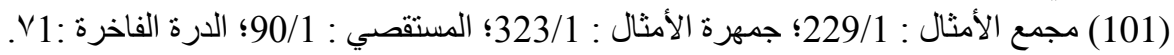

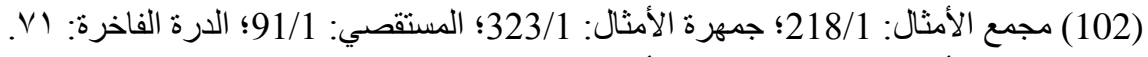

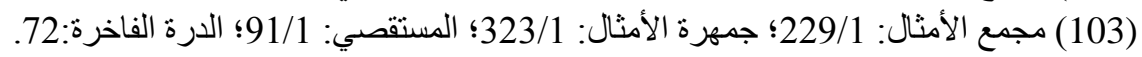

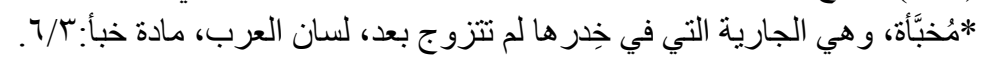

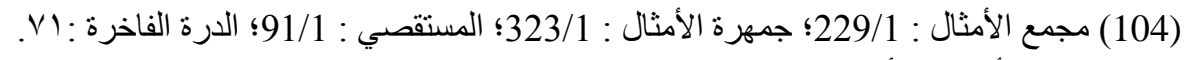

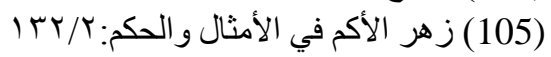

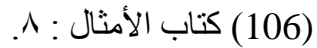

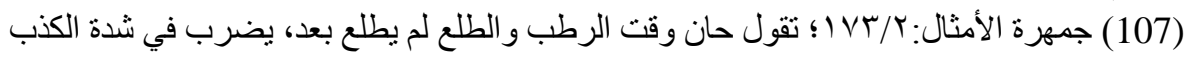

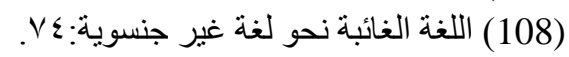

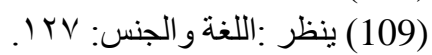

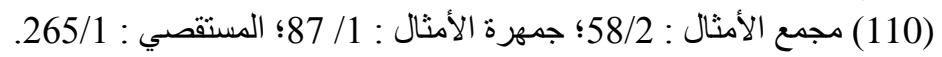

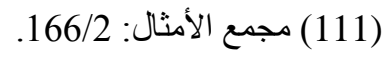

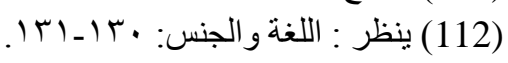

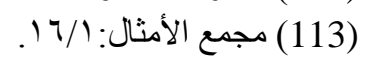

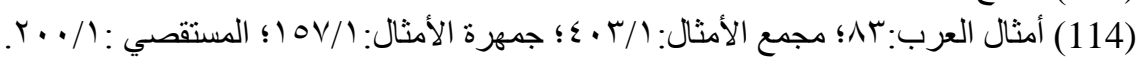

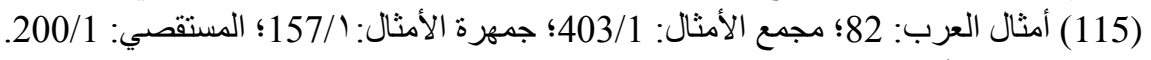

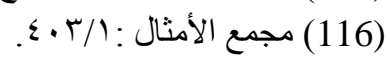

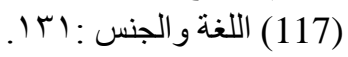

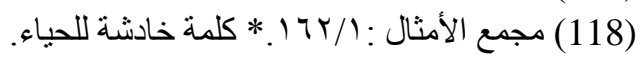

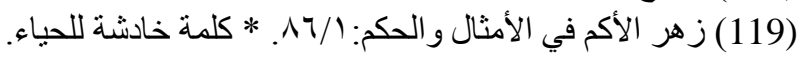

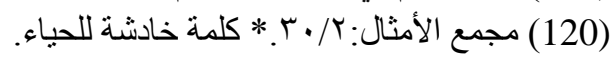

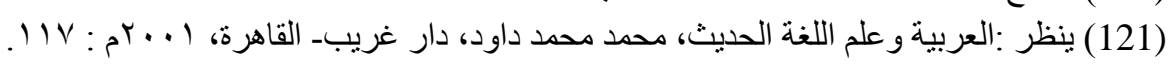

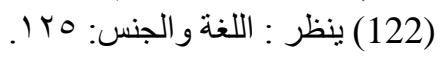

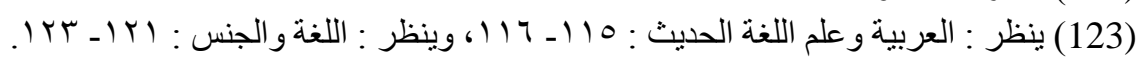


العدد (20) (أبريل 2021

Volume (20) April 2021

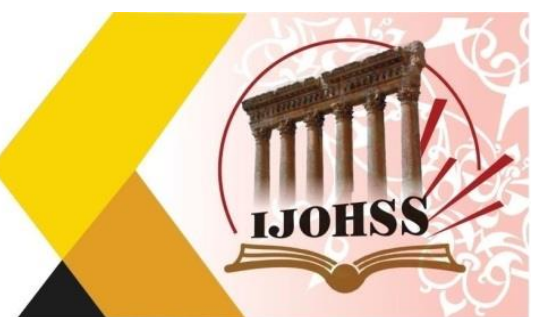

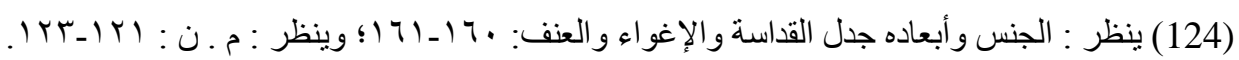

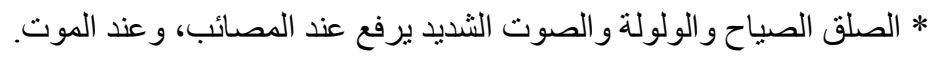

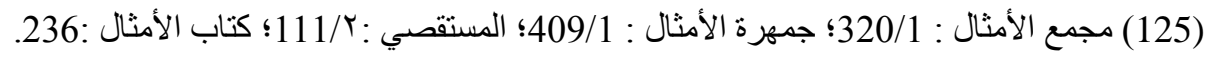

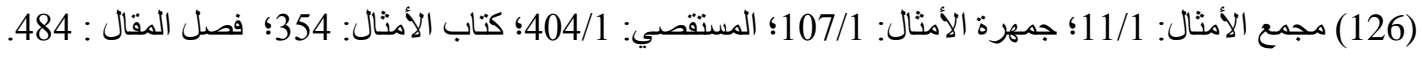

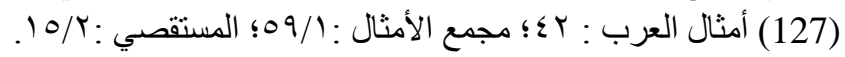

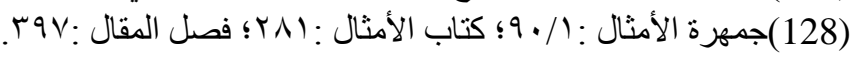

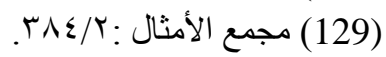

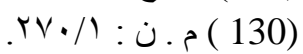
(131)

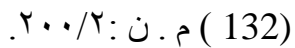

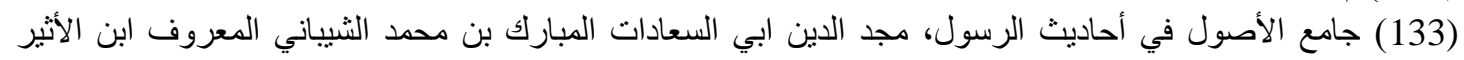

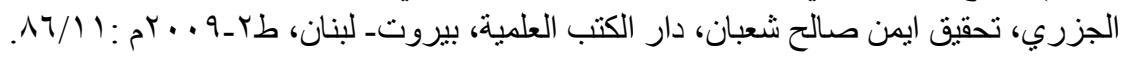

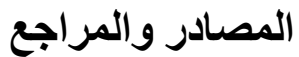

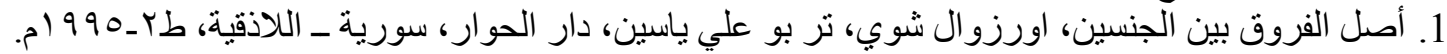

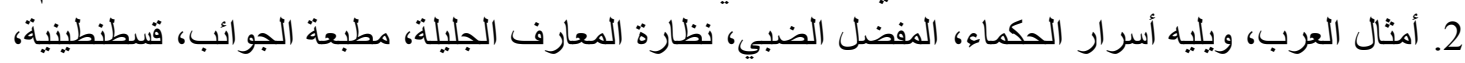

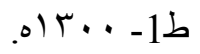
3. الأمثال العربية دراسة تاريخية تحليلية ، عبد المجيد قطامش، دار الفكر العربي، دمشق ـ سورية، طا ـ

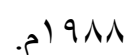

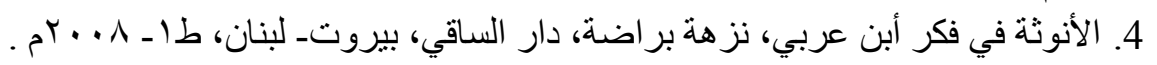

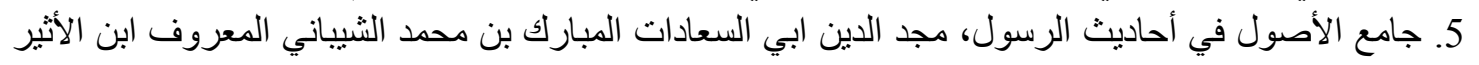

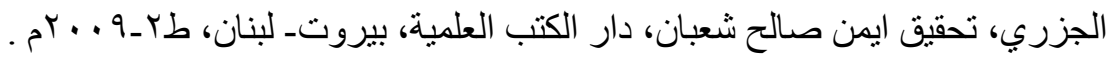

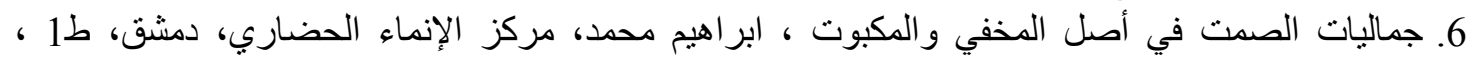
. 7. جمهرة الأمثال، أبو هلال الحسن بن عبدالله بن سهل العسكري، تح: احمد عبد السالم، دار الكتب العلمية،

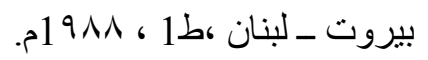

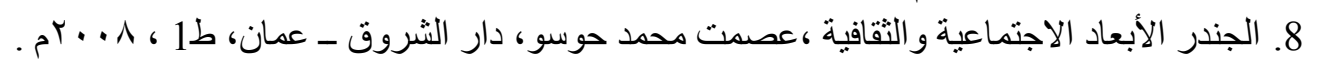

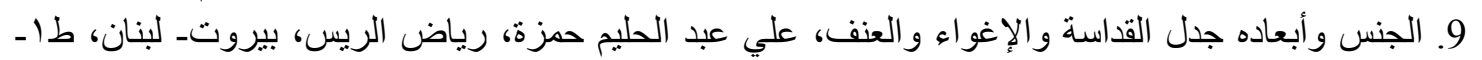

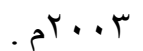

10. الحجاج في قصص الأمثال مقاربة سردية تداولية ، عادل علي الغامدي، المكتبة الوطنية ـ الأردن، ط1 ، 15 11. الخصائص، ابو الفتح عثمان ابن جني، تحقيق محمد علي النجار، تقديم عبد الحكيم الراضي، الهيئة العامة

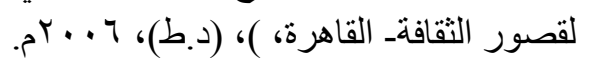
12. الدرة الفاخرة في الأمثال السائرة، لإلمام حمزة بأهة بن الحسن الأصبهاني، تحقيق: عبد الحميد قطامش، دار

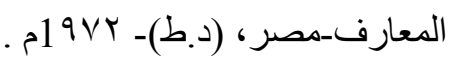
13. زهر الأكم في الأمثال والحكم ، الحسن اليوسي، تح: محمد حجي، محمد الأخضر، دار الثقافة، البيضاء ـ

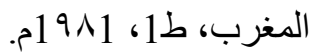
14. سوسيولوجيا الغزل العربي الثعر العذري نموذجا، الطاهر لبيب، نرجمة مصطفى المسناوي، مركز

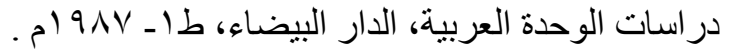




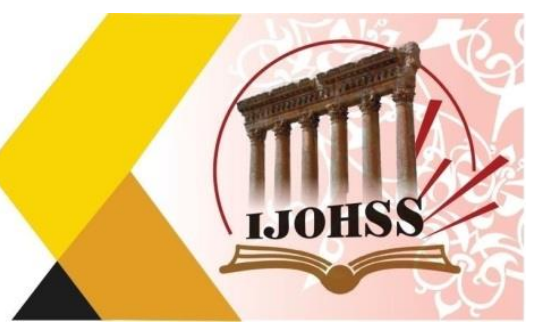

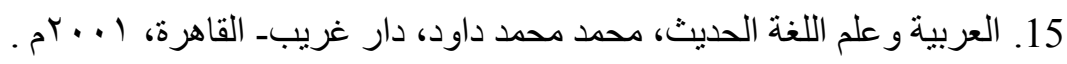

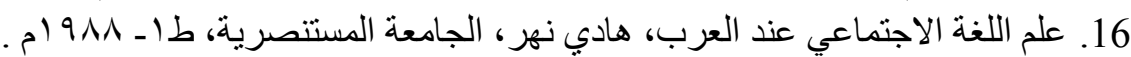

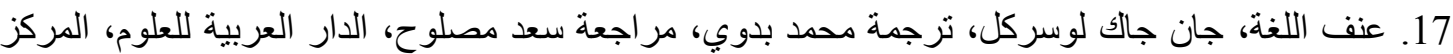

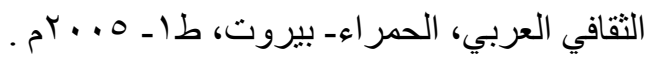

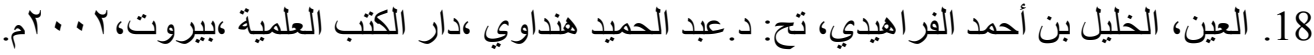

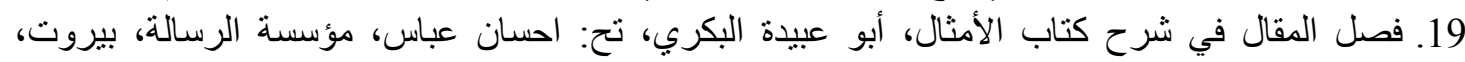

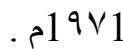

20. قاموس الأسماء العربية والمعربة وتفسير معانيها، حنا نصر الحتّي، دار الكتب العلمية، بيروتـ لبنان، طســ . 21. كتاب الأمثال ، عبد الملك بن قريب الأصمعي ، منشورات الهيئة العامة السورية للكتاب، وزارة الثقافة،

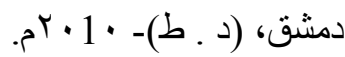
22. الكتاب، سييويه، تحقيق عبد السلام محمد هارون، مكتبة الخانجي- القاهرة، بو 99 ام.

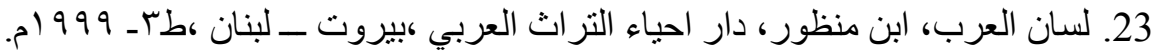

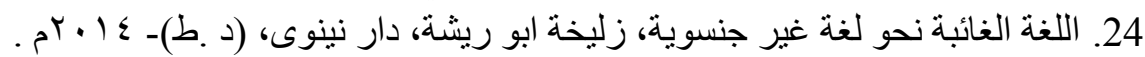

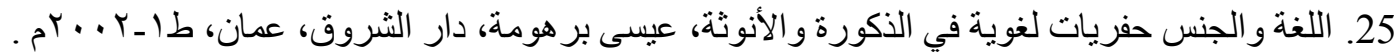

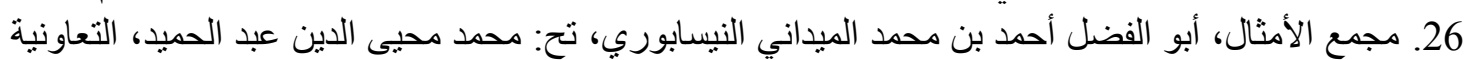

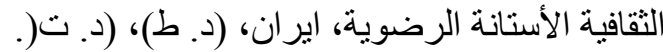

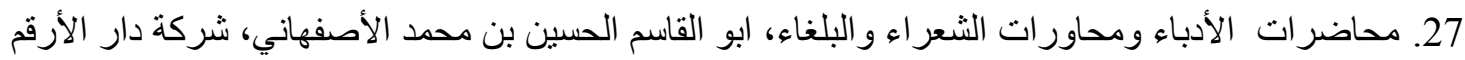

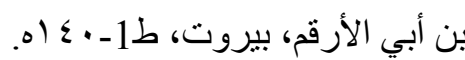

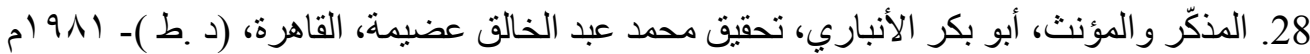

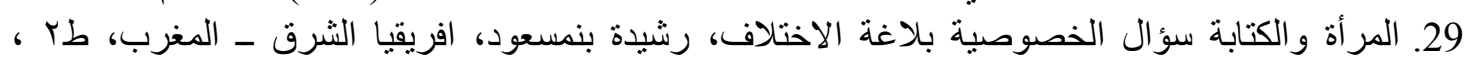

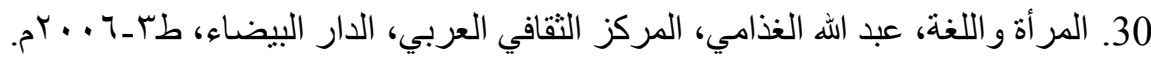

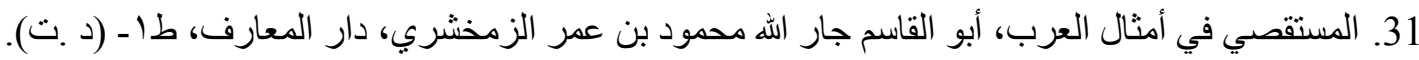

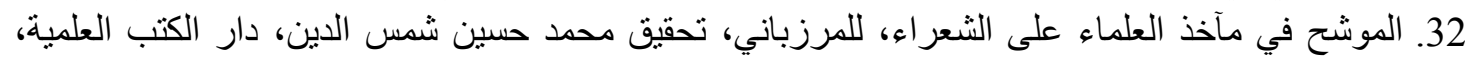

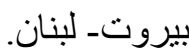
33. النظام الأبوب و إنشكالية تخلف المجتمع العربي، هشام شر ابي، مركز در اسات الوحدة العربية، بيروتـ لبنان،

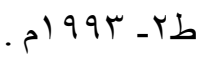

$$
\text { المجلات والدوريات }
$$

1. قيمة الأنوثة المتدنية رؤية في التراث النيات النقدي عند العرب، جابر خضير جبر، مجلة القادسية في الأداب و العلوم

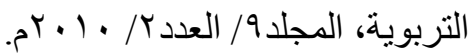

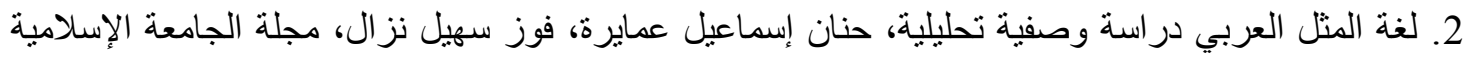

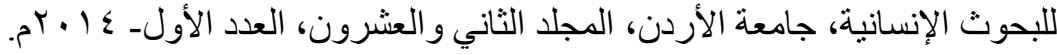




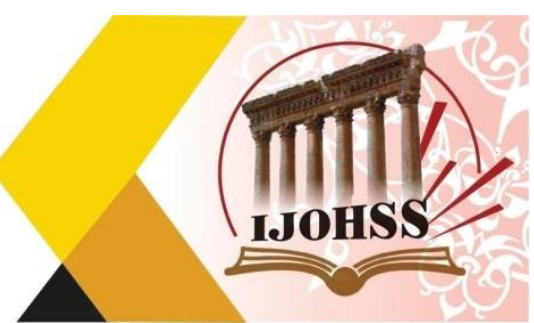

\section{References}

1. The origin of the differences between the sexes, Uruzwal Shwe, Ter Bu Ali Yassin, Dar Al-Hiwar, Syria-Lattakia, 1995-2.

2. The proverbs of the Arabs, followed by the secrets of the wise men, Al-Mukhid AlDhaby, The Great Knowledge of the Great, Al-Jawa'ib Press, Constantinople, i-1300 AH.

3. Arab proverbs, a historical and analytical study, Abd al-Majid Qatamesh, House of Arab Thought, Damascus - Syria, 1988 - 1 st.

4. Femininity in the thought of Ibn Arabi, Nozha Barada, Dar Al-Saqi, Beirut Lebanon, 1st - 2008 AD.

5. The Collector of Fundamentals in the Hadiths of the Messenger, Majd al-Din Abi al-Saadat al-Mubarak bin Muhammad al-Shaibani, the well-known Ibn al-Atheer alJazari, edited by Ayman Salih Shaaban, Dar al-Kutub al-Ilmiyya, Beirut - Lebanon, 2 2009.

6. The aesthetics of silence in the origin of the hidden and repressed, Ibrahim Muhammad, Center for Cultural Development, Damascus, 1st Edition, 2002 AD.

7. A collection of proverbs, Abu Hilal Al-Hassan bin Abdullah bin Sahl Al-Askari, U: Ahmed Abdul-Salem, Dar Al-Kutub Al-Alami, Beirut - Lebanon, 1st Edition, 1988 AD.

8. Gender, Social and Cultural Dimensions, Ismat Muhammad Hosu, Dar Al-Shorouk - Amman, 1st Edition, 2008 AD.

9. Sex and its Dimensions The Controversy of Holiness, Seduction and Violence, Ali Abdel-Halim Hamzah, Riad Al-Rayyes, Beirut-Lebanon, I-1-2003.

10. Al-Hajjaj in Proverbs Stories: An Interdisciplinary Narrative Approach, Adel Ali Al-Ghamdi, The National Library - Jordan, 1st Edition, 2015 AD.

11. Characteristics, Abu Al-Fath Othman Ibn Jinni, investigation by Muhammad Ali Al-Najjar, presented by Abdel-Hakim Al-Radi, General Authority for Cultural Palaces - Cairo, (D. T), 2006 AD.

12. The luxurious pearl in the proverbs, by Imam Hamza bin Al-Hassan Al-Asbahani, edited by: Abd Al-Hamid Qatamesh, Dar Al-Maarif - Egypt, (d. T) - 1972 AD.

13. Zahr Al-Akam in Proverbs and Rulings, Al-Hassan Al-Yousi, Tah: Muhammad Hajji, Muhammad Al-Akhdar, Dar Al-Thaqafa, Al-Bayda - Morocco, 1st Edition, 1981 AD.

14. Sociology of Arabic spinning, virgin poetry as a model, Al-Taher Labib, translated by Mustafa Al-Masnawi, Center for Arab Unity Studies, Casablanca, 1st-1987.

15. Arabic and Modern Linguistics, Muhammad Muhammad Daoud, Dar Gharib Cairo, 2001 AD.

16. Sociolinguistics among the Arabs, Hadi Nahr, Al-Mustansiriya University, 1-1988 AD.

17. Violence of language, by Jean-Jacques Losercle, translated by Muhammad Badawi, by Saad Maslouh, Arab House of Sciences, Arab Cultural Center, Al-Hamra Beirut, 1-2005. 


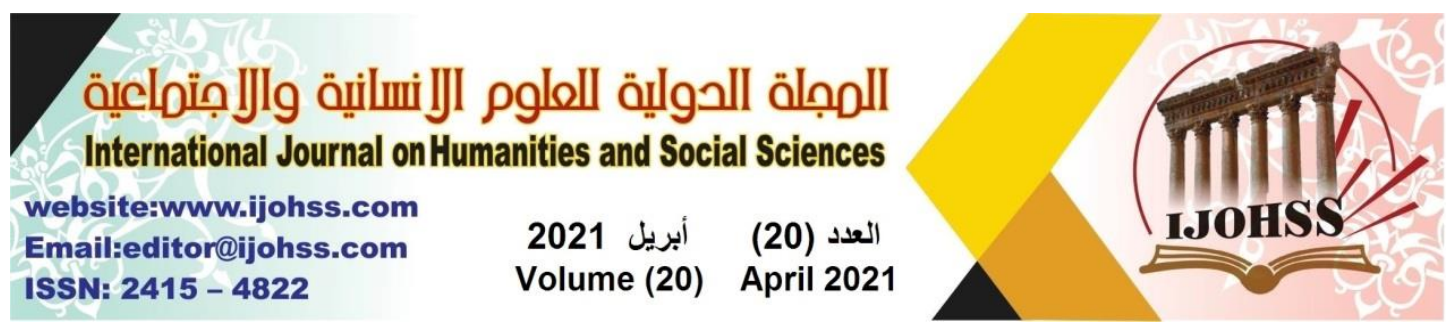

18. Al-Ain, Al-Khalil bin Ahmed Al-Farahidi, under the title: Dr. Abdul-Hamid Hindawi, Dar Al-Kutub Al-Ilmiyya, Beirut, 2002 AD.

19. Chapter of the article on the explanation of the book of proverbs, Abu Ubaidah alBakri, Tah: Ihsan Abbas, Foundation for the Message, Beirut, 1971 AD.

20. Dictionary of Arabic and Arabized Names and their Interpretation of their Meanings, Hanna Nasr Al-Hatti, Dar Al-Kutub Al-Ilmiyya, Beirut - Lebanon, 200303.

21. The Book of Proverbs, Abd al-Malik ibn Qareb al-Asma'i, Publications of the Syrian General Book Authority, Ministry of Culture, Damascus, (d. I) - 2010.

22. The book, Sibawayh, edited by Abd al-Salam Muhammad Haroun, Al-Khanji Library - Cairo, 1992 AD.

23. Lisan Al Arab, Ibn Manzoor, House of Revival of Arab Heritage, Beirut Lebanon, 3 - 1999 AD.

24. The Absent Language Towards a Non-Sexual Language, Zulekha Abu Risha, Dar Nineveh, (Dr. T) - 2014 AD.

25. Language and Sex: Linguistic excavations in masculinity and femininity, Issa Barhuma, Dar Al-Shorouk, Amman, 1st - 2002 AD.

26. Complex of Proverbs, Abu al-Fadl Ahmad bin Muhammad al-Midani al-Nisaburi, under: Muhammad Muhyiddin Abd al-Hamid, The Cultural Cooperative of Astana Razavi, Iran, (d. I), (d. T.).

27. Lectures by writers and conversations of poets and rhetoricians, Abu al-Qasim alHusayn ibn Muhammad al-Isfahani, Dar Al-Arqam Ibn Abi Al-Arqam Company, Beirut, 1-140AH.

28. The masculine and feminine, Abu Bakr al-Anbari, edited by Muhammad Abd alKhaliq Adimah, Cairo, (D. T) - 1981

29. Women and Writing, the Question of Privacy, Rhetoric of Difference, Rachida Benmasoud, East Africa - Morocco, 2nd Edition, 2002 AD.

30. Women and Language, Abdullah Al-Ghadhami, the Arab Cultural Center, Casablanca, 2003-06.

31. The Investigator in Proverbs of the Arabs, Abu al-Qasim Jarallah Mahmoud bin Omar al-Zamakhshari, Dar al-Ma'arif, 1- (d.

32. Al-Muwashah in Scholars's Ways to Poets, by Mirzabani, edited by Muhammad Husayn Shams al-Din, Dar al-Kutub al-Ilmiyya, Beirut - Lebanon.

33. Patriarchy and the problem of the backwardness of Arab society, Hisham Sharabi, Center for Arab Unity Studies, Beirut - Lebanon, 2/1993 AD.

\section{Journals and periodicals}

1. The value of inferior femininity, a vision in the critical heritage of the Arabs, Jaber Khudair Jabr, Al-Qadisiyah Journal of Literature and Educational Sciences, Volume 9 / Issue 2/2010 AD.

2. The language of the Arabic proverb, an analytical descriptive study, Hanan Ismail Amayrah, Fouz Suhail Nazzal, Journal of the Islamic University for Human Research, University of Jordan, Volume Twenty-second, Issue 1 - 2014 AD. 